\title{
WestVirginiaUniversity
}

THE RESEARCH REPOSITORY @ WVU

Graduate Theses, Dissertations, and Problem Reports

2010

\section{Global mindedness and dispositions towards diversity in the classroom}

Ras T. Acolatse

West Virginia University

Follow this and additional works at: https://researchrepository.wvu.edu/etd

\section{Recommended Citation}

Acolatse, Ras T., "Global mindedness and dispositions towards diversity in the classroom" (2010).

Graduate Theses, Dissertations, and Problem Reports. 4557.

https://researchrepository.wvu.edu/etd/4557

This Dissertation is protected by copyright and/or related rights. It has been brought to you by the The Research Repository @ WVU with permission from the rights-holder(s). You are free to use this Dissertation in any way that is permitted by the copyright and related rights legislation that applies to your use. For other uses you must obtain permission from the rights-holder(s) directly, unless additional rights are indicated by a Creative Commons license in the record and/ or on the work itself. This Dissertation has been accepted for inclusion in WVU Graduate Theses, Dissertations, and Problem Reports collection by an authorized administrator of The Research Repository @ WVU.

For more information, please contact researchrepository@mail.wvu.edu. 


\title{
Global Mindedness and Dispositions towards Diversity in the Classroom
}

\author{
Ras T. Acolatse \\ Dissertation submitted to the \\ College of Human Resources and Education \\ at West Virginia University \\ in partial fulfillment of the requirements \\ for the degree of \\ Doctor of Education \\ in \\ Curriculum \& Instruction: Communication Studies
}

\author{
Ardeth Deay Ph.D., chair \\ Peter Oehlkers, Ph.D. \\ Deborah Hendricks, Ed.D. \\ Elizabeth Dooley, Ed.D. \\ Perry Phillips, Ed.D.
}

Department of Curriculum \& Instruction/Literacy Studies

Department of Communication Studies

Morgantown, West Virginia

2010

Keywords: Teacher Education; Global Education; Multicultural Education; Intercultural Communication 


\title{
Global Mindedness and Dispositions towards Diversity in the Classroom
}

\author{
Ras T. Acolatse
}

This study examined gl obal mindedness and dispositions towards diversity in the classroom between two groups of teacher candidates. One group had obtained a bachelors degree before starting the teacher education program while the other group started the teacher education program without a college degree. The global mindedness scale (GMS) and the Teacher Multicultural Attitude Scal e developed by Hett (1993) and Ponterrotto (2004) respectively were used for the study.

The study was guided by four research questions and four corresponding hypotheses. Univariate t-tests were use to analyze data for research questions one and two to determine the difference between the mean scores of the two groups of teacher candidates. For research question three, a correlation analysis was used to determine the relationship between teacher candidates' global mindedness and dispositions towards diversity in the classroom. A multivariate analysis of variance (MANOVA) was used to determine the interactions between the demographic variables and the latent variables of global mindedness and dispositions towards diversity.

Though both groups of teacher candidates were positively disposed to global mindedness and diversity in the classroom, the study found that teacher candidates with a prior college degree showed a more positive orientation towards gl obal mindedness and diversity issues in the classroom. The study al so found a positive relationship between global mindedness and disposition toward diversity in the classroom. Thus the more gl obally minded teacher candidates were the more positively they were disposed to diversity issues in the classroom and vice versa. Finally, the study found that the demographic variables of age, teaching experience, travel/study abroad experience were positively related to global mindedness and disposition towards diversity in the classroom. 


\section{Dedication}

\section{Daughter}

I dedicate this dissertation to my daughter, Nubuklenam, whose name literally and figuratively means a new day/era has dawned for me.

May you grow in the wisdom and traditions of the great secrets of the cosmos: The Laws of Forgiveness and Attraction.

\section{Nieces/Nephews}

I also dedicate this dissertation to all of you for making Uncle Pee proud. May you continue to grow in grace and wisdom. Do not relent on your pursuit of intellectual and moral enlightenment.

\section{My Students}

I duly dedicate this dissertation to all my students from Mamrpobi North 5 Primary School, Wa Secondary School, Wesley Girls' High School, West Virginia University, Glenville State College, West Virginia Wesleyan College, University of Phoenix, and Westwood College.

Continue to flourish in all you do. Do not forget to say thank you to those who have helped you in various ways.

$$
\text { My Best Friend }
$$

Philip Wola Adadevoh, I dedicate this dissertation to you for the gift of friendship. Though we have not been in touch that much lately, I still think about you all the time and I know you do the same.

$$
\text { My Family }
$$

I dedicate this work to you in recognition of your abundant love and selflessness. 


\section{Acknowledgement}

Yes, I gave up and quit many times! Nevertheless, here I am today writing this acknowledgement to thank the people who kept lifting me up every time I stumbled and fell along the path of dissertating. Truthfully, it is impossible to thank all who have made it possible for me to finally see the light at the end of the long, lonely, dark tunnel of a doctoral work and dissertation. Ther efore, in this acknowledgement I am going to be very selective in thanking the most important people in my life. If I failed to mention your name either inadvertently or for lack of space, please note that I am every inch grateful for all your help and support throughout the years. My Dissertation Committee

I wish to thank my committee for helping me through the onerous process of writing my dissertation. I am particularly grateful to them because they did not lose faith in my ability though I quit many times along the way. Without this astounding group of people, my dissertation would have been dead on arrival. Their profound patience and understanding have made all the difference.

First, my sincerest thanks go to Dr. Ardeth Deay. Dr. Deay as I affectionately call her despite her insistence that I call her Ardeth has been a remarkable friend and mentor to me through these daunting years. Incontestably, I would not have made it this far had it not being for her incredible patience with me and her abiding faith in my competence. Above all, Dr Deay provided excellent critique and positive feedback on my work - a balanced view without which my work would have been intellectually half-baked. As chair of my committee, she did an excellent job providing guidance, definition and focus to the committee through the entire process in a very efficient manner. Without Dr. Deay's salutary presence in my life and on my committee, my 
dissertation would have been jettisoned into the dustbin of unfinished dissertations. To Dr. Deay, I am ineffably grateful! My mother and siblings extend their regards and gratitude to you for making all the difference in my life.

Second, I want to thank Dr. Peter Oehlkers for agreeing to take the place of Dr. Virginia Richmond when she could no longer serve on my committee. Peter was my professor at Emerson College in Boston where I pursued my masters in Management and Organizational Communication. His class on Intercultural Communication is what piqued my interest in intercultural issues. It is instructive to note that a significant portion of the concepts espoused in my literature review was introduced to me for the first time by Peter. Though Peter joined my committee late, he has been a great contributor to the overall quality of my work. When I met Peter at Emerson College, I knew that I wanted to drink from his fountain of knowledge. He has shown me what it truly means to be an interculturalist, and for this, I am immensely grateful .

Third, I wish thank Dr. Deborah Hendricks for demystifying Statistics to the extent that a functionally innumerate person like me could understand clearly and be able to teach others. Yes, she made Statistics both fun and useful! The knowledge that I gained in both of her Statistics classes helped me tremendously during this dissertation process. Her guidance through my dissertation and doctoral program has been very helpful. She labored tirelessly over my methods and results sections and provided invaluable feedback. I know that without shedding her Statistics light on my document, many statistical anomalies would have hidden in the darkness only to rear their ugly heads at an unholy hour. I am truly grateful for her help and guidance.

Fourth, I wish to thank Dr. Elizabeth Dooley. I thank you for preventing me from producing a less than complete dissertation. Your deeply penetrating questions at 
my prospectus meeting gave me enough food for thought which made me to re-think my

dissertation. Without your suggestions, my product would have been incomplete. In addition, I thank you for showing a genuine inter est in my life as a person as well as a student. My mother never ceases to mention how warm and welcomed she felt when I bought her to your office in Allen Hall. It is because of people like you who make me think very differently about being an educator.

Lastly, I wish to thank Dr. Perry Philips. Thank you for your dedication in working with the international students in the department. Year after year, I found my either directing international students to you for consultation or hearing other international students saying how kind you have been to them. I particularly want to thank you for your gentle but firm questioning and suggestions during my prospectus meeting. Those questions and suggestions have undoubtedly shored up the academic quality of my product.

My Departments

First, I must thank the professors who have had the most impact on my intellectual habits: Dr. Ardeth Deay, Dr. Peter Oehlkers, Dr. Perry Philips, Dr. Deborah Hendricks Dr. Virginia Richmond, Dr. James C. McCroskey, Dr. Scott Myers, Dr. Pat Obenauf, Dr. Iaonne, Dr. Scott Bower, Dr. Sam Stack, Dr. Dempsey, Dr. Hall,

In addition to the faculty, I wish to thank the entire support staff for working behind the scenes to make my life as a doctoral student a little less frustrating. However, I cannot but single out a couple who deserve special thanks: 
Barbara Rocovich, I want to thank you for your gift of friendship, help, and support throughout my doctoral journey. I cannot count how many times I have called on you for help with administrative paperwork or help typing and formatting my papers. My special thanks to you for helping format and type the research instruments I used for my dissertation as well as your help with the IRB protocol. When I left Morgantown two years ago, you became my representative. I cannot thank you enough for saving me long drives to Morgantown to take care of stuff. Your compassion and willingness to help are hal Imarks of true friendship. I am truly happy to call you my friend.

Char Allen, thank you so much for helping me with all of the paperwork that is required to get through all of the graduation process. I particularly thank you for your patience and encouragement since I have had to schedule my defense and cancelled on you twice. I am not sure how many students have had to reschedule multiple times, but you al ways welcomed me to your office with a comforting smile. Not that you would mind, but I am glad to say that I will not have to reschedule again:-)

Finally, I wish to thank al of the doctoral students I have worked with over the years: Dr. Weena Gaulin, Dr. Jason Wrench, Dr. Constinia Charbonnette-Jordan, Dr. Angela Derk, Ms. Angela Fiore, Mr. Cyprien Lokko, Ms. Deaton King, Ms. Tara Brooks, Eveldora Wheeler, Zoa Williams, All of these amazing individuals have had such a huge impact on the way I understand life and this field.

The Presidents' Office of Social Justice It took the vision of then President of WVU, David C. Hadesty and Jennifer Mclntosh, AAO to institute the Minority Doctoral Program through which I came to WVU. I wish to thank both of you for giving me the opportunity to attain a doctoral 
degree. I also want to thank you Mr. Charlie Morris for being instrumental in the affairs of the Minority Doctoral Program. Jennifer and Charlie deserve another special thank you for serving as proxy parents for most of us. I thank you both for welcoming us into your homes on several occasions to unwind and to celebrate the small successes some of us may have chalked al ong the way. My tribute to the office will not be complete without mentioning the great work dome by the graduate students who have been working behind the scenes to make the office run. Ms. Gabby St Leger, Ms. Dee Curtis, and Ms. Ro Hutchinson, please accept my sincerest thanks for all you hard work in making sure my tuition waivers are processed on time.

My Family

The last group of people who deserve my thanks and gratitude is my family. I wish to thank my mother, Mrs. Theresa Alba Dede Acolatse and father, Mr. Theophilus Kwashie Acolatse (deceased) for "drilling education into my head." I particularly thank them for not giving up on their hitherto headstrong and incorrigible son. I also want to thank my siblings: Joyce, Doris, Antoinette Love, Albert, Derrick, and Theophilus for sacrificing their share of the "family cake" to enable me to pursue my educational goals and aspirations. I wish to say a big thanks to you all for being considerate, understanding and for being my greatest cheerleaders. The thought of disappointing you kept me going anytime I thought of giving up on my doctoral dream.

I also want to thank my wife, Faustina for blessing our family with a beautiful baby girl $\longrightarrow$ a blessing that propelled me out of the doldrums. Though we do not see eye to eye on many things, I wish to thank you for sticking it out with me as I labored through this dissertation process. You have been a true help meet! 
My family's acknowledgement would not be complete without thanking my host and "adopted" American families: Moone-Childs and the Evans family of Windsor, CT and Long Island, NY. Your abiding love and faith in me have been great motivators. However, I wish to thank you for expanding my definition of family. Now, it is imperative to single out Rev Dr. Shirle Moone-Childs to offer my ineffable gratitude for paving the way for me to come to America and for taking me in and treating me like her own son. Auntie Shirle, Akpe na wo---meaning "thank you" in my mother tongue, Ewe.

Finally, to Jah be the glory! 


\section{Table of Contents}

Title Page

Abstract

ii

Dedication

iii

Acknowledgements

iv

Table of Contents

$\mathrm{X}$

List of Tables

xi

Chapter 1: Introduction

Chapter 2: Literature Review

Chapter 3: Methodology

Chapter 4: Presentation and Analysis of Data

Chapter 5: Discussion

References

Table 1

Table 2

Table 3

105

Table 4

Table 5

107

Table 6

Table 7

109

Appendix A: Informed Consent For

Appendix B: Combined Survey Instruments

Appendix C: Permission Letters to Dean Faculty of HR\& 


\section{List of Tables}

Table 1: Frequency Statistics for Demographic Study Variables (N=102)

Table 2: Latent Variable constructs for Study, and Associated Response Item Numbers, According to Survey Instrument $(\mathrm{N}=102)$

Table 3: Descriptive Statistics for Summed Latent Variable Constructs as Relates to Inferential Hypotheses ( $\mathrm{N}=102)$

Table 4: Summary of Results for Independent Samples t-tests as Relates to Hypothesis 1, Comparison of Teacher Candidates who Possessed a Bachelor's Degree $(\mathrm{n}=51)$ vs.

Teacher Candidates Who Had Not Previously Obtained a Bachelor's Degree $(n=51)$.

Table 5: Summary of Results for Independent Samples t-tests as Relates to Hypothesis 2, Comparison of Teacher Candidates who Possessed a Bachelor's Degree $(\mathrm{n}=51)$ vs. Teacher Candidates Who Had Not Previously Obtained a Bachelor's Degree $(n=51)$.

Table 6: Summary of Significant Results for Pearson's Product Moment Correlation (Hypothesis 4a) and One-Way MANOVA Analyses (Hypotheses 4b-4g) as Relates to Hypothesis 4, Comparison of Sample Independent Demographic Variables with Study Latent Variable Constructs $(\mathrm{N}=102)$

Table 7: Summary of Inferential Analysis Results for Study vis-à-vis the Research Questions ( $\mathrm{N}=102)$ 


\section{CHAPTER 1 INTRODUCTION}

In recent years, the issues of globalization and cultural diversity have gained increasing attention in higher education. As the international community moves toward greater interdependence, globalization is driving a revolution in educational institutions. This transformation is being shaped by the demands to prepare labor for participation in the global economy and to prepare citizens to participate in the international polity (Torres, 2002). Policymakers and the public have concluded that in order for the United States to be competitive in this era of globalization, schools and universities must produce the human capital necessary to meet the demands of the new economy (Artiles, 2003). In addition to globalization, the United States is experiencing a shift in demographic trends, including an increase in cultural diversity (Galambos, 2003). Increased diversity is evident in American higher education, where minority undergraduate enrollment is projected to rise from $29 \%$ in 1995 to $37 \%$ in 2015(Carnevale \& Fry, 2000, cited in Pike, 2002). Faced with this fundamental demographic change, leaders in the public and private sectors have called on the higher education establishment to prepare students to function effectively in a diverse society (Pike, 2002).

In response, teachers and teacher educators are increasingly called upon to provide educational opportunities to ameliorate such a condition, both on the domestic as well as the global front, while having few tools and little experience to draw on. The vast majority of the teaching force in most countries around the world represents the majority culture, whereas the number of minority or underrepresented students continues to increase ( Banks, 2004 ). This, coupled with the fact that most current teachers have had 
relatively few, if any, significant intercultural experiences and are relatively inexperienced with regard to global affairs, leaves a tremendous gap that must be filled (Kirkwood, 2001). In short, to meet the needs of the 21st century, schools must successfully teach many more students from increasingly diverse backgrounds while preparing them for a much more complex, interdependent world that most teachers themselves are not familiar with. Consequently, the nature of teacher preparation and the settings in which students learn to teach must undergo substantial change.

How we might apply what we know about culture learning in teacher education programs to better prepare new teachers to encounter this increasing global diversity has been the focus of considerable work during the past few decades. Numerous teacher educators point to the critical role that extended field experiences offer in assisting preservice teachers to improve their understanding and ability to work with students of diverse backgrounds (Cushner \& Mahon, 2002; Sleeter \& Grant, 2003). Researchers from the fields of cross-cultural psychology and intercultural training consistently emphasize the important role experience plays in culture learning (Quezada, 2004). That is, developing the skills that enable an individual to live and work effectively among individuals from cultures other than their own requires significant, long-term, direct personal interaction with people and contexts different from those in which one is most familiar.

Classroom encounters where culturally diverse students and teachers interact can result in different types of intercultural communication faux pas experiences. These encounters demonstrate the importance of (a) embarking upon scholarly inquiry into this phenomenon, (b) school curriculum and pedagogical changes, and (c) teacher in-service 
and pre-service training. Changing classroom environments and increasing interactions between culturally diverse teachers and students reflect a need to examine intercultural communication issues in the classroom. Additionally, multicultural classroom encounters illustrate a need to assess teachers' views in relation to their sense of, connection to, and interest in the culturally diverse communities their students represent.

The vast immigration of foreign-born to America, the increase in the socioeconomic lower class, the growing numbers of naturalized citizens and the wave of xenophobia have influenced performance and communication in organizations, which, in turn, impacts upon effectiveness (Commission on the Status of Women, Summer 2001; Garcia, 1999; Gibson, 1999; Hofstede, 1980; Macedo, 2000). Furthermore, workplace issues have influenced individuals’ attitudes and behaviors toward culturally different organizational members (Beamer \& Varner, 2001).

Within the last twenty years, American educational institutions have had to start dealing with cultural issues in classrooms, in teaching, and in curriculum development. Specifically, the American public school system is increasingly confronted with cultural diversity issues that impact upon such issues as classroom management, curriculum design, teacher-student cultural communicative similarities and differences, interculturalism, multiculturalism, and teacher motivation (Evans \& Reynolds, 2004; Helms, 2004).

Communication and culture are two important elements in organizational life. Furthermore, the culture from which individuals come affects the way they communicate (Martin \& Nakayama, 2007). The present day American classroom of culturally diverse students confronts educational organizations with the challenge of how to instruct 
culturally diverse students while incorporating cultural inclusiveness in instruction, curriculum design, and motivation (Bennett, 1990; Davies, 2006; Evans, 2006). In short, American educational organizations are confronted with issues concerning cultural communication (Landis, Bennett \& Bennett, 2004; Mitchell, 1999). Unquestionably, public school teachers' views of the world and its global community will manifest themselves in their classroom communication.

Teachers’ global-mindedness (Hett, 1993), worldview (Sampson \& Smith, 1957; Samovar \& Porter, 2001), and global self-concept (Hayakawa, 1963) profoundly influence their interactions with their culturally diverse students. As teachers communicate with their culturally diverse students, they make predictions about "the effects, or outcomes of their communication behavior; that is, they choose among various communicative strategies on the basis of predictions about how the person [students] receiving the message will respond” (Miller and Steinberg,, 1975, cited in Gudykunst \& Ting-Toomey, 1988, p.18). The same sentiment was echoed by Samovar, Porter \& McDaniel (2007).

\section{Conceptual Framework}

The conceptual framework for the study draws upon the worldview of global mindedness and attitude toward cultural diversity.

\section{Global Mindedness}

According to Hett (1993), a global perspective is an ecological worldview that promotes the unity of humankind and the interdependence of humanity, universal human rights, loyalties that extend beyond national borders, and a future-oriented perspective. We are living in an interdependent world, and a citizen in any one country is compelled 
to learn about other countries. Welch's (2002) rationale for globalizing universities included the preparation of scholars and graduates who are internationally knowledgeable and competent, and the need to address the interdependent nature of the world (environmentally, culturally, economically, socially) through scholarship, economic priorities, and maintenance of scientific and technological competitiveness. Global perspective is a relatively new concept; therefore, the research literature on this topic is embryonic. Several researchers (Odell, Williams, Lawrence, Gartin, \& Smith, 2002; Zhai \& Scheer, 2002) revealed that overseas experiences tended to have a positive influence on students' global perspectives. Consequently. Friedman, believes that with the rapid shrinking of our world, U.S. institutions cannot afford the consequences of failing to prepare their citizens for participation in world affairs Attitude Toward Diversity

An attitude toward cultural diversity is defined as one's feeling, thought or disposition about the differences among people with respect to race, class, ethnicity, socioeconomic level, religious affiliation, age, language, physical and mental ability, sexual orientation, and other human attributes (Grogan \& Eshelman, 1998; Nisha \& Niranjan, 2003).

The U.S. population is becoming increasingly diverse in ethnic, racial, and national backgrounds. To be successful in this diverse society, Americans must have cross-cultural skills, knowledge, and sensitivity. The changing ethnic texture of the U.S. population has major implications for all of the nation's institutions, including schools, colleges, universities, and the work force (Banks, 1997). These institutions must be restructured and transformed in order to meet the needs of the different kinds of people 
who will work in and be served by them. The inclusion of diversity into student development should not be left to any one university office or administrator (Apple, Kenway, \& Singh, 2005; Franzway, 2005). Research has confirmed that students' openness to diversity was related to the overall diversity of the student body, opportunities for positive interactions among diverse groups of students, and exposure to curricula that include knowledge about diverse groups (Pike, 2002; Noddings, 2005).

Historically, global perspective and diversity are two distinct concepts with global perspectives emphasizing worldwide phenomena and diversity focusing primarily on ethnicity within the United States (Baker, 1999; Banks, 1997; Merryfield, 1993, cited in Banks, 1997). However, in recent years, many scholars and educators have made conceptual connections between these two fields of study because both are critical components of educational programs if schools are to prepare young people for effective participation in their local and global communities (Merryfield, 1996). The most important forces for cooperation between the two are the similarities of the goals and content (Baker, 1999). Baker and Merryfield indicated that both fields intended to promote equity and social justice, to improve intergroup and global understanding and relations, to improve intercultural communication, to reduce stereotyping and prejudice, and to help people comprehend human diversity and human commonalities. Based on this framework, global perspectives and attitudes toward cultural diversity will be examined in this study.

\section{Statement of the Problem}

Experiencing increased cultural, racial, and ethnic student population shifts, the United States public school system and elementary schools, in particular, have in the last 
twenty years seen the largest culturally diverse student population increase in its educational school history. This increased presence of diverse students in an American public school system introduces numerous variables that affect educational goals and objectives and instructional practices. To address these diversity issues in the domain of teacher education, professionals have recognized the need for teacher education to address diversity and global issues both in theory and in practice so as to prepare teacher candidates for the global and diverse milieu in which they will live, work and play. Unfortunately, many teacher education programs do not emphasize global and diversity issues enough let alone measure the efficacy of the few programs they have in place.

Against this backdrop, this study sought to assess the value orientations of teacher candidates as it relates to their global mindedness and attitude towards diversity

\section{Purpose of the Study}

Despite the growing trend toward increasingly diverse classrooms around the world, the workforce that teaches them remains remarkably stable and homogenous across a number of regions, particularly in the USA (Capella-Santana, 2003). This is an unfortunate and avoidable circumstance, due to inequities in social class and ethnicity as well as weaknesses in teacher recruitment, preparation and employment. While there are many examples of successful strategies to diversify faculty and staff (e.g. career ladder preparation programs in universities), researchers estimate that this trend will only continue to increase as the number of globally mobile professionals traveling around the world with their families increases (Hayden et al., 2000).

Research also indicates that culturally based misunderstandings arising from incongruities between the life experiences and cultural backgrounds of teachers and 
students can and do result and can be devastating to the learning process (Easter et al., 1999; Van Hook, 2000). In response, many studies investigating possible solutions have emerged and these are detailed in the sections to follow. Some researchers believe that teachers can be trained through a variety of mediums to overcome their culturally based biases and become more pluralistic, flexible, and open-minded in their thinking (Razzano, 1996; Hayden et al., 2000; Thompson, 2002; Capella-Santana, 2003). Others, however, are not so sure, citing mixed results of teacher education programs (CochranSmith et al., 2004). Nonetheless, developing a sense of global mindedness and a positive attitude towards cultural diversity can serve as an impetus for overcoming some ethnocentric perceptions, behaviors, and ways of being in the world that can affect not only a teacher's efficacy in the culturally- and linguistically-diverse classroom, but also his/her ability to succeed in an increasingly diverse world (Van Hook, 2000).

Thus, the purpose of this study was to explore teacher-candidates' global mindedness and disposition towards cultural diversity in the classroom. In doing so, the study sought to deepen the understanding of teacher candidates' global mindedness and attitudes toward cultural diversity in the classroom.

\section{Research Questions}

Study of teacher candidates' global mindedness and disposition towards cultural diversity in the classroom was guided by the following questions:

1. How globally minded are teacher candidates?

2. What are teacher candidates' attitudes toward cultural diversity? 
3. Is there a relationship between teacher candidates' level of global mindedness and attitude toward cultural diversity?

4. Is there a difference among teacher candidates' global mindedness and attitude towards diversity based on the following demographics:
a. Age
b. Gender
c. Ethnicity
d. Teaching Experience
e. Course Work
f. International Travel/Study Abroad
g. Exposure to Domestic Diversity
h. Religious Persuasion/Worldview
i. International Languages Spoken

\section{Significance of the Study}

The current demographics of the teacher force and entering teacher candidates in the United States indicate that teachers are mainly European American, middle-class, and monolingual. For many, their experience with diverse cultures is limited (Irvine \& Armento, 2001) Therefore, one can assume that teacher candidates may not have reality based beliefs and knowledge about culturally and linguistically diverse students. Providing students of all cultural backgrounds with equal opportunities to succeed in school seems to be a matter of knowing how to teach such students. It is also a matter of believing that every child has a right to have access to high status knowledge and that every child can learn (Gay, 2002). 
Studying teacher candidates' global mindedness and attitudes about cultural diversity in the classroom is a significant enterprise. The findings of this study has the potential to help teacher educators to better prepare and equip teacher candidates' with the culturally relevant tools that will help them thrive and succeed in their future multicultural classroom. This study will also add to the burgeoning scholarship on the interplay between culture and education.

\section{Limitations of the Study}

As with any study, this study has limitations that must be addressed. This research has two major limitations that need to be addressed:

1. Limitations imposed by sample population

2. Limitations imposed by participants perception

\section{Population Limitations}

The first limitation with this study is that the data came from two groups of teacher candidates at a large mid-Atlantic university. One group entered the teacher education program with bachelor’s degrees in various disciplines and will usually graduate with a master's degree in education after two years. The other group of teacher candidates has no bachelor's degrees and will usually graduate with a master's degree in education after five years of study. While these groups of students were admittedly a convenience sample and the results in this study are not necessarily generalizable to the general public, their global mindedness and attitude towards diversity in the classroom varied widely. However, a better population sample would include professional teachers to broaden the perception base and generalizability of the findings. 


\section{Perception Limitations}

A second limitation to this study is that it is based solely on the participants' perceptions of global mindedness and diversity in the classroom. The participants were asked to respond to a series of perception questions. While this vague wording broadened the possible experiences, it forced participants to think of an experience and then try to answer the questions based on that experience.

\section{Definition of Terms}

For the purpose of clarity in this study, the following definitions are offered:

- Global-Mindedness is a worldview in which ones sees oneself as connected to the world community and feels a sense of responsibility for its members. This commitment is reflected in an individual's attitudes, beliefs, and behaviors.

- Responsibility is a deep personal concern for people in all parts of the world, which surfaces as a sense of moral responsibility to try to improve conditions in some way.

- Cultural Pluralism is an appreciation of the diversity of cultures in the world and belief that all have something of value to offer. This is accompanied by taking pleasure in exploring and trying to understand other cultural frameworks.

- Efficacy is a belief that an individual's actions can make a difference and that involvement in national and international issues is important.

- Globalcentrism is thinking in terms of what is good for the global community, not just what will benefit one’s own country. A willingness to make judgments based on global rather than ethnocentric standards.

- Interconnectedness is an awareness and appreciation of the interrelatedness of all 
peoples and nations which results in a sense of global belonging or kinship with the "human family" (Hett,1993).

- Liberal/General Education is "an approach to learning that empowers individuals and prepares them to deal with complexity, diversity, and change. It provides students with broad knowledge of the wider world (e.g. science, culture, and society) as well as in-depth study in a specific area of interest. A liberal education helps students develop a sense of social responsibility, as well as strong and transferable intellectual and practical skills such as communication, analytical and problem-solving skills, and a demonstrated ability to apply knowledge and skills in real-world settings” (American Association of Colleges \& Universities, 2010). 


\section{CHAPTER 2 LITERATURE REVIEW}

This chapter reviews the theoretical and empirical literature germane to the exploration of teacher candidates’ global mindedness and attitude towards cultural diversity in the classroom. The literature review draws mainly from the fields of intercultural communication, multicultural education, and educational psychology. Drawing from both qualitative and quantitative paradigms, studies reviewed encompass research reviews, research reports and articles, as well as theoretical papers. The eclectic nature of the review is intended to bring to the forecourt of the reader's attention, the wide range of issues and perspectives pertaining to the interplay among culture, teaching, and learning.

This chapter is organized in two major distinct but interrelated sections: The first section focuses on the relationship among culture, communication, and multicultural classroom. The second section addresses practical considerations that pertain to teaching culturally diverse students.

\section{Intercultural Communication and Multicultural Classrooms}

This section will report on literature related to the study from an intercultural communication perspective. The report will cover the following pertinent topics: Culture and Communication, Dimensions of Cultural Difference, and the Interplay of Culture and Communication in Multicultural Classrooms. Understanding these concepts is critical to appreciating the intercultural communication component of this study.

\section{Culture and Communication}

Culture is a multidimensional construct encompassing a rich array of methodological and theoretical perspectives. It is instructive to note that there is no 
known universally agreed upon definition of culture. Jandt's (2004) summary is used as the working definition for this study. This is so because Jandt's definition mirrors a concatenation of various historical and comparative points of view. It provides the most central characteristic of culture, that is, "culture is a way of life based on some system of shared meaning” (Danesi \& Perron, 1999, p. 23). Jandt opines that, for a given group, culture refers to "the totality of that group's thought, experience, and patterns of behavior and its concepts, values and assumptions about life that guide behavior and how those evolve with contact with other cultures” (p. 7).

Hofstede and Hofstede (2005) classified these elements of culture into four categories that often manifest cultural differences: symbols, heroes, rituals, and values. Symbols are words, gestures, pictures, or objects that carry a unique meaning only recognized as such by those who share the culture. Heroes are persons, alive, or dead, real or imaginary, who posses characteristics that are highly prized in a culture and thus serve as role models for behavior. Rituals are collective activities, technically superfluous to reaching desired ends, but which, within a culture, are considered socially essential. Values, as the core of culture, are broad tendencies to prefer a certain state of affairs to others, such as evil versus good, ugly versus beautiful, dangerous versus safe. Hofstede and Hofstede also stress that culture is always a collective phenomenon, learned instead of innate. Using the analogy of the way computers are programmed, they call the patterns of thinking, feeling, and potential acting people begin to acquire from early childhood and learn throughout their lifetime, "mental programs," or "software of the mind" (p. 3). Put differently, culture is a social system shared by as group of people that defines its members' perceiving, thinking, and acting. Culture is acquired through the process of 
socialization, and becomes a part of people’s identities.

Communication and intercultural communication. Although people learn to communicate with others at a very early age, communication is a complex process and is hard to define. If we seek the origin of this word, we can find that "communication is derived from the Latin communicare, meaning to share with or to make commons, as in giving to another a part or share of your thoughts, hopes and knowledge” (Jandt, 2004, p. 28). Communication occurs because people have the need to interact and share with each other. Gudykunst and Kim (1992) summarize several basic elements of communication, but the following were selected for this review because of their relative relevance to this study: communication is a symbolic activity; communication is a process involving encoding and decoding of messages, and communicators make predictions about the outcomes of their communication. These elements are relevant because they emphasize the idea that culture and communication are inseparable; and since teaching and learning are primarily communicative in nature, one cannot gloss over the importance of teachers understanding the cultures their students.

First, communication is a symbolic activity. Communication involves the use of symbols. Symbols are used to stand for, or represent something else. What is important is that "symbols are symbols only because a group of people agree to consider them as such. There is no natural connection between any symbol and its referent; the relationship is arbitrary and varies from culture to culture” (p. 6). Second, communication is a process involving encoding and decoding messages. Encoding refers to the process of putting our thoughts, feelings, emotions, or attitudes into a form recognizable by others. Decoding is the process of perceiving and interpreting, or making sense of, incoming messages and 
stimuli from the environment. How we encode and decode messages is influenced by our symbolic and experiential background, not only our unique individual experiences but those of our shared group and culture. Third, communicators make predictions about the outcomes of their communication. When people communicate, they predict the effects of their communication behaviors and responses of others. Such predictions are made based on their knowledge of the culture's routines, and their expectations that others share their knowledge as well. This process is not always conscious.

From the above submissions, it can be posited that communication is an element of culture, and culture and communication are inseparable just like a two-sided coin. "Culture is a code that we learn and share, and sharing and learning require communication. ...Culture cannot be known without communication, and communication can only be understood with an understanding of the culture it supports” (Jandt, 2004, p. 29).

Intercultural communication, simply defined, refers to communication of people from different cultural backgrounds (Jandt, 2004). According to Dogancay-Aktuna (2005), intercultural communication is "the process occurring when the producers and receivers of a message belong to different cultures” (p.100). Combining the conceptualizations of culture and communication, Gudykunst and Kim (1992) define intercultural communication as "a transactional, symbolic process involving the attribution of meaning between people from different cultures” (p. 14) These definitions can be applied to multicultural classrooms where teachers, teaching methodology, and materials are the products of one culture, while the receivers are members of other cultures. 
According to Gudykunst and Kim, cultural influences include those factors involved in the cultural ordering process such as cultural values, norms, and rules. Sociocultural influences are those involved in the social ordering process, such as social group membership, self-concept, role expectations, and interpersonal relationship. Psychological influences are those involved in the personal ordering process , which mainly includes stereotypes, attitudes, and personal expectation for the communicators. Environment also influences our encoding and decoding of messages; location, climate, and our perception of the environment, affect our interpretation of the incoming stimuli and the predictions we make about other people's behavior. All of the above elements play roles in the actual communication process between people from different cultures in various ways, and often without awareness. Cultural Norms, Rules, and Expectations

Cultural norms, rules, and expectations are three important concepts to understand cultural differences and their influences on intercultural communication including multicultural classroom interaction. According to Gudykunst (2004), norms are "guidelines of how we should behave or should not behave that have a basis in morality" (p.43) and rules are "guidelines for ways we are expected to communicate” (p. 43). Compared to norms, rules are usually not based in morality. We learn cultural norms and rules from parents, school, religious institutions, peers, and mass media. Since norms and rules tend to vary systematically across cultures, knowing the norms and rules guiding our own behavior as well as those guiding others' behavior can help us communicate more effectively. 
Based on culture, especially cultural norms and rules, we anticipate and predict how others will communicate with us. This is what Gudykunst (2004) calls expectation. He gives an example to illustrate the potential problems with expectations that can occur when people from different cultures communicate. In American culture, students are generally expected to keep eye contact when communicating with their teachers. However, in African culture, students are generally expected to keep their gaze away when communicating with their teachers. To maintain eye contact with your teacher or superior is considered disrespectful in most African cultures. If an American and an African are both following their own cultural communication rules and are not aware that the other person's rules are different, they will inevitably violate each other's expectation and misinterpret each other's behaviors. If this happens between an American teacher and an African student in a classroom and the teacher does not know this rule, it is very possible that the teacher will interpret the student's behavior as impolite or dubious. In this sense, Gudykunst emphasizes that expectations are culturally based.

At the same time, norms, rules, and expectations for appropriate communication are often hidden, and embedded in the socialization process whereby our particular ways of doing and seeing are passed down from one generation to the next (Breslin, 2000). When others violate our rules and expectations of how they should act in various situations, we are often left confused, annoyed, and even label others as strange or incompetent, but ignore that others may have a different understanding of communicative interaction from ours. Norms, rules, and expectations often involve a group’s preferred ways of understanding and interacting, and these ways of seeing and doing have become arbitrary over time and are simply maintained because they were the ways of parents and 
grandparents. If we are not forced to question why we maintain these ways of being, it is likely that we will continue acting in the habitual ways (Chamberlain, 2005).

\section{Dimensions of Cultural Variability}

In order to explain cross-cultural differences and their potential influences on people’s thinking and acting, theorists across disciplines have developed several dichotomous dimensions. They mainly include individualism-collectivism, low- andhigh context communication, low- and- high power distance, masculinity-femininity, and low- and- high uncertainty avoidance. In the ensuing paragraphs, the dimensions are discussed in relation to how they manifest in educational settings.

Individualism-collectivism. This dimension refers to how people define themselves and their relationships with others. In an individualistic culture, emphasis is placed on an individual's goals over group goals, the interest of the individuals prevails over the interest of the group, and the ties between individuals are loose. By contrast, in collectivist culture, group goals have precedence over individual goals and the interests of the group prevail over the interests of the individual. In such a culture, people are integrated into strong cohesive in-groups (Gudykunst, 2004; Jandt, 2004) In other words, “Individuality is more important than group membership in individualistic cultures,” and “Collectivist cultures require that individuals fit into their groups” (Gudykunst, 2004, p. 46).

Based on a large-scale intercultural research in more than seventy countries, Hofstede (2005) uses an individualism index to assess people’s values towards individualism. The results indicate that the United States and many European countries have high scores on this index; the score of many countries in Asia (such as Singapore, 
Thailand, and Vietnam) and Latin America (Costa Rica, Panama, and Columbia) are much lower. They summarize some key features between individualistic and collectivist culture. For example, in an individualistic culture (IC), children learn to think in terms of "I”; while children in collectivistic cultures (CC) learn to think in terms of "we." In IC, speaking one's mind is a characteristic of an honest person; while in CC, harmony should always be maintained and direct confrontations should be avoided. In IC, trespassing leads to guilt and loss of self-respect; while in CC, trespassing leads to shame and loss of face for self and group.

Undoubtedly, these differences can be employed in the analysis of multicultural classrooms. In many classrooms in North America, it often happens that the teachers from a more individualist culture teach some students from collectivist cultures. A typical complaint from such teachers is that these students do not speak up, not even when the teacher puts a question to the class. Hofstede and Hofstede analyze this and point out, "For the student who conceives of him-or- herself as part of a group, it is illogical to speak up without being sanctioned by the group to do so" (p. 96). If the teacher wants s students to speak up, the teacher should address a particular student personally. They suggest teachers use small group discussions to increase student participation. After the small group discussion, then every group is asked to appoint a spokesperson. In this way, "individual answers become group answers, and those who speak up do so in the name of their group” (p. 97).

Low-and high context communication. The concept of low-and high context cultures was popularized by Hall (1976). Context, here, is operationalized as "the environment in which the communication takes place and which helps define the 
communication" (Jandt, 2004, p. 33). A low-context message is one in which "the mass of information is vested in explicit code” (p. 70). A high-context message, in contrast, is one in which "most of the information is either in the physical context or internalized in the person, while very little is in the coded, explicit, transmitted part of the message" (Hall, 1976, p. 79). From the definitions, we can see that while individualismcollectivism defines broad differences between cultures, the low-and high context scheme focuses on cultural differences in the communication process. Low-and high context communication are the predominant forms of communication in individualistic and collectivistic cultures respectively (Gudykunst, 2004), though both of these forms are used in both cultures.

Based on the characteristics of these two forms of communication, Gudykunst points out that members of individualistic cultures who use low-context communication tend to communicate in a direct way; while members of collectivist communication tend to communicate in an indirect fashion, and it is often ambiguous. Direct communication focuses on clarity, while extremely indirect messages may not be easily interpreted by listeners. Some forms of indirect messages can be interpreted accurately, when the individual is given "knowledge of the context and the person transmitting the messages" (p. 202). Statements such as "Say what you mean, "and "Get to the point" illustrate the kind of direct and precise communication that is valued by members of low context. If a teacher from a low-context orientation wants to tell students to pay attention and start their work, she of he might announce to the student, "Please stop talking and get out your books,” while a teacher with a high-context orientation might say, “The bell has rung,” thus implying that the instructional time has started (Chamberlain, Guerra \& Garcia, 
1999).

In addition, for members of high-context cultures, groups play an important role in their lives, and they share a great deal of group information and highly developed sense of group identity with others. In order to communicate effectively with them, it is important to understand their group affiliations, since much of the meaning of their messages will be embedded in that knowledge and identity. Whereas individuals with low-context communication style are characterized as direct and explicit, individuals with high-context communication style are characterized as providing rich detail and depending on shared experiences, from which listeners can infer the meaning of a message (Hall, 1976).

Low- and high power distance. Power distance is defined as "the extent to which the less powerful members of institutions and organizations within a country expect and accept that power is distributed unequally” (Hofstede \& Hofstede, 2005, p. 46). Individuals from high power distance cultures accept power as part of society. As such, superiors consider their subordinates different from themselves and vice versa. While people in low power distance cultures believe power should be used only when it legitimate and prefer expert or legitimate power (Gudykunst, 2004).

There are some presentations of power distance and differences between the high power distance and low power distance cultures in the education setting as Hofstede and Hofstede (2005) summarize: In high power distance cultures, teachers are treated with respect, the educational process is teacher centered, and teachers outline the intellectual paths to be followed. Teachers are supposed to initiate all communication, and students in class speak up only when invited to; teachers are never publicly contradicted or criticized 
and treated with utmost dereference even outside of schools. There the teacher is a guru, a term derived from the Sanskrit word for "weighty" or "honorable," which in India and Indonesia is, in fact, what a teacher is called. By contrast, in low distance cultures, the educational process is student centered, with a high premium placed on student initiative; students are expected to find their own intellectual paths and rhythms. Students make uninvited interventions in class, and they are supposed to ask questions when they do not understand something. They argue with teachers, express disagreement and criticism in front of the teachers, and show no particular respect to teachers outside school. Effective learning in such a system depends very much on whether the supposed two-way communication process between students and teachers is indeed established.

Masculinity-femininity. The focus of the cultural masculinity-femininity dimension of cultural variability is on gender roles in cultures. Masculinity pertains to societies in which "emotional gender roles are clearly distinct: men are supposed to be assertive, tough, and focused on material success, whereas women are supposed to be more modest, tender, and concerned with the quality of life” (Hofstede \& Hofstede, 2005, p. 120). Femininity pertains to societies in which emotional gender roles overlap; both men and women are supposed to be modest, tender, and concerned with the quality of life” (p. 120). People in highly masculine cultures value things, power, and assertiveness, while people in cultures low on masculinity or high on femininity value quality of life and nurturance. Members of highly masculine cultures emphasize differentiated sex roles, performance, ambitions, and independence, while members of cultures low on masculinity value fluid sex roles, quality of life, service, and interdependence” (Gudykunst, 2004). 
Based on longitudinal studies, Hofstede \& Hofstede (2005) summarize the presence of this dimension in the educational setting from several perspectives. In masculine cultures, "students try to make themselves visible in class and compete openly with each other unless collective norms put a limit to this," while in feminine cultures, "assertive behavior and attempts at excellence are easily ridiculed" (p. 137). Criteria for evaluating teachers and students also differ between masculine and feminine cultures. “On the masculine side, teachers' brilliance and academic reputation and students' academic performance are the dominant factors. On the feminine side, teachers' friendliness and social skills and students’ social adaptation play a big role” (p. 139). Uncertainty Avoidance. Uncertainty is a very natural feeling or perception in peoples' communication especially among people from different cultural backgrounds. As Marris (1996) indicates, "uncertainty is a fundamental condition of human life” (p. 1), and people can never have complete predictability about anything or anyone. "What constitutes uncertainty depends on what we want to be able to predict, what we can predict, and what we might be able to do about it” (Marris, 1996, p. 16). When people become aware of their inability to predict or explain others' behavior, attitudes, feelings, and so forth, then uncertainty often arises (Gudykunst, 2004). There are mainly two types of uncertainty present in people's interaction: predictive uncertainty and explanatory uncertainty. The former refers to uncertainty about predicting others' attitude, feelings, beliefs, values, and behavior, while the latter refers to uncertainty people have about understanding others' behavior.

Members of cultures high in uncertainty avoidance have a lower tolerance for uncertainty and ambiguity and there is a strong desire for consensus, and deviant 
behavior is not acceptable. They try to avoid ambiguity, and therefore develop copious rules and rituals for virtually every possible situation in which they might find themselves. People in low uncertainty avoidance cultures accept dissent and take risks more than people take in high uncertainty avoidance cultures (Gudykunst, 2004).

In schools, students from high uncertainty avoidance cultures expect their teachers to be experts who have all the answers, and intellectual disagreement in academic matters can be felt as a personal disloyalty. Students tend to favor learning situations with "precise objectives, detailed assignments, and strict timetable” (Hofstede \& Hofstede, 2005, p. 178). While students from low uncertainty avoidance cultures accept a teacher who says “I don’t know, “and intellectual disagreement in academic matters can be seen as a stimulating exercise. Students like "open-ended learning situations with vague objectives, broad assignments, and no timetable” (p. 179), and they expect to be reward for originality.

\section{Communication in Multicultural Classrooms}

Informed by the basic concepts and theories of culture and communication, one can safely infer their roles and potential influences when they are applied to the multicultural classroom. Hofstede (2005) indicates that today more and more intercultural encounters happen in the classroom. One of these encounters is between local teachers and foreign, migrant, or refugee students; “different value patterns in the cultures from which the teachers and students have come from are one source of problems” (p. 332). Both teachers and students bring to school their own cultural backgrounds, and many of their characteristics are hidden from each other. Teachers' cultural backgrounds influence their philosophy of education, the materials they choose, their methods of instruction, 
their expectations of the students, and their ways of interacting with the students. Bt the same token, cultural background influences the students’ way of learning and communicating with adults and peers. Cultural differences and expectations for acceptable behavior caused by them often clash because of the hidden dimension of culture (Trumbull, Greenfield, \& Quiroz, 2003). Chamberlain et al, (1999) propose that intercultural communication should play a crucial role in student-teacher interactions in today’s schools and classrooms, so that increasing teachers' understanding of intercultural communication will contribute to more culturally responsive teaching and effective interactions with students. However, little attention has been given to the hidden dimensions of culture that can pose difficulties for culturally diverse students in the mainstream classroom (Betsinger, Garcia, \& Guerra, 2000). In order to help these students overcome such difficulties, teachers have to be better prepared. This task is complex and challenging, but its magnitude is great, given the cultural discontinuity between students and teachers, as well as the resulting possibilities for cultural clashes.

\section{Educating Diverse Students}

The extant literature has shown how cultural differences can result in poor communication and become the basis for misunderstandings and misperceptions. The multicultural classroom is a place where theories of cultural differences and intercultural communication can be applied and further investigated. Educating diverse students has its distinct characteristics and challenges, and needs educators’ special attention, knowledge, and skills. In this section, three salient topics are addressed: Teachers’ Awareness of Cultural Influences on Learning and Teaching, Teachers’ Roles in Facilitating Diverse Students Learning, and Interventions that Improves Teachers’ Work with Diverse 
Students.

Teachers’ Attentiveness to Cultural Influences on Classroom Dynamics

Cognition and learning styles. The use of "learning styles” and “cognitive styles” in this study refers to cultural ways of learning. Researchers in cultural studies often use these two phrases interchangeably. Research has shown that cultures influence students' learning in different aspects. Cognitive style and process, an important element for students' learning is one of the psychocultural influences as presented in Figure 1. The way in which each of us understands text and language is grounded in our cultural, social, and historical backgrounds. Things we have learned are closely related to the demands of the environment in which we grew up. "A person will become good at doing the things that are important to him or her and that he or she has occasion to do often” (Hofstede \& Hofstede, 2005, p. 333). Aslmeng-Boahene and Klein (2004) argue that a learner’s cognitive style addresses the manner in which an individual derives meaning from the environment, and how that person interprets and processes information from that environment. They further suggest, “cognitive development is of particular importance in diverse situations because learning can only take place if the situation mirrors the individual's backgrounds” (p. 48). However, teachers may not necessarily be aware of the diverse students' ways of thinking brought about by their various cultural backgrounds, and thus devalue them as not correct or not valid.

One example is found in the research of Rothsein-Fisch, Greenfield, and Trumbull (1999). They observed a classroom where most students were Latino, and most teachers were Anglo. In one observation, a kindergarten teacher held up an egg and asked her class to describe it. The first student called on said, “Mi abuellos [grandparents] come 
over on Sundays and we eat miiigas [an egg dish].” The teacher replied, "No, I want you to describe the egg." A second student was called on, and proceeded to say, "It's hard and white on the outside and wet and yellow on the inside. The teacher then responded, "Yes, that's an excellent description of the egg." Can we say that the first student's description is not correct? Chamberlain (2005) analyzes this example by stating that the teacher defines description of an egg from the perspective of concrete, physical dimension, but the first student's response indicates that she defines the description from the angle of functional (how do you use eggs) and relational (who is important when you use eggs) dimensions. Both responses reflect equally valid ways of describing eggs, but the thinking processes are different. However, the teacher's response to the two students suggests that the second student has a good and valid way of thinking, while the response from the first student is wrong, which is actually an unjustified evaluation.

One of the most notable differences in cognitive process is presented in storytelling and narrative writing. Hyon and Sulzby (1992) and Mikkelsen (1990) find that students with a low-context orientation use a logical sequential framework, while students with a high-context orientation concentrate their story and written narrative on episodic events that revolve around people and their relationship. For teachers with lowcontext orientation, these stories can appear to consist of random, disconnected snippets that are not structured, have no flow, and follow no rules. Delpit (1995) addresses the same issue: mainstream culture favors topic-centered narratives, which are characterized by a linear flow of events, a limited number of main characters, specific setting and time, a problem that occurs in the story, and a resolution to that problem by the end of the story. By contrast, some other groups favor topic associative or episodic style. Stories in 
this style tend to shift from setting to setting, are nonlinear, usually include more characters, provide a greater context, and are longer than topic-centered narratives. These kinds of stories can be commented upon by members from the same cultural group as "well-formed” stories, but people from other cultures may see them as "terrible," “incoherent,” and even think that student "exhibits language problems.” De Jong and Harper (2005) also emphasize that bilingual writers often do not meet the "standard" writing norms for different genres used in schools where low-context communication is dominant. By overlooking the influence of different communication orientations and the student's first language, teachers may interpret these differences as deficits in the second language or even in ability to think.

Related to cognitive style and processing ability of the diverse students is their learning style. For many years, educators have designed curriculum and instruction to cater to a secluded group like the white, middle-class students, and expected other learners to conform. This policy disadvantages minority students, and creates a large number of educational losers (Manning \& Baruth, 2000). For example, students from collectivist backgrounds are more likely to thrive and do well cooperative learning environments and activities. When individual work is emphasized, these students face more challenges and even risks (Delpit, 1995). Trumbull et al. (2003) summarize another example to explain the difference in learning styles between students from collectivistic and individualistic cultures. In collectivist cultures, the value of physical objects is primarily that they mediate social relationships, and infants spend most of their time with other human beings. A toy would be of little value outside its role in an interaction with another person. By contrast, individualistic cultures tend to emphasize technological 
knowledge of the physical world as a way of facilitating independence. "Parents are likely to hope and believe their children will be verbally competent and able to construct knowledge of the physical world from observing and manipulating toys that stimulate independence and technological mastery” (p. 73). From this statement, we can see that playing with the same toy does not mean children attain the same result. What they learn about the world and how they learn it, are largely related to their roles in the family, within society, and as learners. All of these learning styles and habits are acquired in the socialization process from early childhood. Therefore, it is important for educators to "know how all students learn, to recognize that students from culturally diverse backgrounds have unique leaning styles, and to determine the most appropriate instructional approaches and techniques” (AsImeng-Boahene \& Klein, 2004, p. 50). From the above arguments, we can posit that learning styles are not simply an individual preference as we might be tempted to assume, and that they are culturally situated and influenced.

Achievement gap. Besides the cognitive and learning styles of diverse students, the achievement gap between some groups of diverse students and mainstream students is also a topic widely discussed by researchers in multicultural education. The two most frequently asked questions about the achievement gap are Who is to blame? and Why are those students not meeting the standards? There are no easy answers for these poignant questions, because the reasons might be more complex than we can fathom. However, some researchers have investigated this problem the perspective of cultural difference and teachers' expectations of these diverse students, which is very germane for our understanding of this issue. As White-Clark (2005) asserts, cultural differences between 
students and teachers can negatively impact student achievement, and teacher misconceptions can lead to diverse students being “misunderstood, miseducated, and possibly mistreated” (p. 42).

One of the related elements is teachers' understanding of the "funds of knowledge” students bring to the classroom. Moll, Amanti, and Neff (1992) investigate the knowledge base of Latino students when entering schools and find that these students entered school with certain "fund of knowledge" in alphabet, written words, basic concepts and categories, and narratives, but these "funds of knowledge" they bring are different from what educators expect. Students from mainstream culture usually share the “funds of knowledge” with mainstream teachers and this knowledge base is attained via socialization and often taken for granted. However, culturally diverse students must be explicitly taught if they are expected to be competent and successful. Hollins (1996) calls this certain knowledge base the "hidden curriculum," in the sense that these are not clearly articulated or posted for all to see. When students do not meet these expectations for prerequisite learning, they enter school at a disadvantage, and risk being called deficient thinkers. In the study of linguistic development and language learning, Menyuk (1999) points out that many native English-speaking children know approximately 6,000 words and basic grammatical knowledge even before first grade. Their knowledge of English is predicated on their experience with language used in meaningful context before schooling. However, diverse students, many of whom are learners of English as a second language, often need more time, opportunities, and help to fully make sense of background knowledge about that language and culture, and at the same time develop their literacy skills. 
Besides a culturally related knowledge base, teachers' low expectations of diverse students can also be a reason for underachievement. As previously analyzed, individuals from different cultural backgrounds often violate the norms, rules, and expectations of each other in a communicative interaction (Brislin, 2000). When this happens in classrooms, teachers may tend to view diverse students as differing from the norm and to understand these differences as a problem rather than as a resource. This will affect the daily interactions between teachers and students, lead teachers to make misattributions about the cause(s) of student's learning difficulties, as well as set low expectations for these students. Teachers with low expectations for a student often underestimate student's learning potential, do not motivate the student by posing only simple questions, and use inappropriate instructions for them. All of these have a negative effect on student learning, progress, and achievement (Garcia \& Guerra, 2004). Given the plethora of research indicating the potentially devastating influence of low teacher expectations, teachers must be cognizant of their expectations and behaviors as well as of how they affect their students. Chamberlain (2005) opines, "It is better for teachers to overestimate students' abilities and adjust expectations accordingly than to underestimate students, never giving them an opportunity to reach their potential” (p. 206).

Because of the achievement gap caused by a variety of reasons, some culturally diverse groups are overrepresented in special education interventions. According to Colombo (2004), culture clashes play a critical role in leading teachers to refer struggling students without disabilities for special education assessment. Chamberlain (2005) takes the learning of second language (L2) as an example. The processes of L2 acquisition are different in many ways from those for first language (L1) acquisition; if teachers do not 
recognize these differences and do not know they are normal when acquiring L2, they will expect these processes to be the same, and may view the difference as related to disability. Therefore, educators must be very careful when assessing their students, viewing the students' difficulties within the context of their cultural groups and language proficiency statuses rather than the teachers' own cultural norms and expectations. Teachers’ Roles in Facilitating Diverse Students’ Learning

With the school population becoming more culturally diverse, teachers' roles are also expected to need some adjustment in order to meet the needs of these students. In multicultural classrooms, teachers are not only educators, but should also be cultural facilitators. As Banks (2001a) indicates, a major goal of education in multicultural settings is to:

Change teaching and learning approaches so that students of both genders and from diverse cultural, ethnic, and language groups will have equal opportunities to learn in educational institutions. This goal suggests that major changes ought to be made in the ways that educational programs are conceptualized, organized, and taught. (p. 12)

Undeniably, teachers play a crucial role in fulfilling this goal, but they may not recognize this. In the study of Betsinger et al. (2000), many participant teachers at the beginning of the designed training programs attributed student success more frequently to parent involvement and resources available in the home and community, and seldom to school or instructional factors, "They did not frame teaching and learning in a cultural context, their views about effective teaching and learning tended to be universalistic, rather than culturally-relativistic" (p. 105). However, by the end of the training program, they had 
the idea that factors contributing to academic underachievement and failure could not, and should be viewed solely in terms of students' and family characteristics. School and teachers' unawareness of the inter-relationship between culture, learning, and teaching could also be big contributors to diverse students' performances. In that case, facilitating diverse students' learning by applying culturally responsive teaching should become an important role in their teaching.

According to Gay and Kirkland (2003), culturally responsive teaching (CRT) is predicated on the assumption that:

(a) multicultural education and educational equity and excellence are deeply interconnected; (b) teacher accountability involves being more self-conscious, critical, and analytical of one's own teaching beliefs and behaviors; and (c) teachers need to develop deeper knowledge about what is being taught, how, and to whom (p. 181).

Some researchers call CRT "socioculturally sensitive pedagogy" (Dogancay-Aktuna, 2005, p. 106).

To be interculturally aware and responsive in today's classroom should be become an integrated part in the role of being an effective teacher, who provides equitable resources for all students regardless of their cultural backgrounds. In fact intercultural awareness as a crucial element of intercultural competence has been adequately argued as a must in the field of intercultural communication and adapted by some researchers in the field of multicultural education.

As Nieto (2000) postulates, one must become a multicultural person before one can become an effective multicultural teacher. A multicultural person, according to 
Gudykunst (2004), should have intercultural competence, which includes motivation, knowledge, and skills. "Motivation" refers to people's desire to communicate appropriately, i.e., in a desirable way, and effectively; "knowledge” refers to people’s understanding of what needs to be done in order to communicate appropriately and effectively; "skills" refer to our ability to engage in behavior in order to communicate appropriately and effective. Bryam (1997) explains the concept of intercultural competence more comprehensively. For him, intercultural competence requires certain attitudes, knowledge, and skills. "Attitudes” refer to curiosity, openness, and "readiness to suspend disbelief and judgment with respect to others' meanings, beliefs, and behaviors" (p. 34). "Knowledge" includes the knowledge of products and practices of one's own and others' cultures as well as the knowledge of the interaction process at individual and societal levels. "skills" comprise those to interpret a document or event from another culture, to explain it and to relate it to one's own culture, to discover new knowledge and make it operational in real communication, and to evaluate critically the practice and products of one's own and others' cultures. Hofstede and Hofstede (2005) use awareness instead of motivation or attitudes, plus knowledge and skills to describe intercultural competence. "Awareness" refers to "the recognition that everybody carries particular mental software for equally good reasons because of the way they were brought up” (p. 359).

If the general categories are adapted to the particular case of multicultural classrooms, it can be said that "awareness" should include the teachers' sensitivity to cultural differences and their influences on students' growth and learning. Teachers should also be aware of their own cultural values and beliefs, and how these affect their 
attitudes and expectations towards diverse students, which influence students' selfconcepts, academic abilities, educational opportunities, and achievement outcomes (Gay 2001). "Knowledge" should include cultural practices, cultural codes, cognitive and learning styles of diverse students, with all of which teachers can culturally decipher the students' thoughts and behaviors from their unique points of view. Finally, the "skills" should include the ability and practice to diversify teaching strategies culturally, to reduce stress, tension, and conflict in the culturally pluralistic classroom, and to create a supportive environment which adequately addresses students' needs, validates diverse cultures, and advocates equitable access to educational opportunity for all (Bennett, 1995).

In conclusion, it can be observed that though the various researchers used slightly different terminology to describe intercultural competence, the elements are virtually the same. Additionally, awareness (or motivation or attitude) is always the first element. As Hofstede and Hofstede indicate, awareness is "where it all starts" (p. 359), and knowledge and skills both follow awareness. It is for reasons of the primacy nature of awareness that this study focuses on teacher candidates' intercultural awareness instead of the other two elements. As Greenleaf et al. (1994) argue, teachers' mental lives play a crucial role in their interpretation of classroom information and how to use that information in a culturally relative way. Without taking a close look at the teachers' awareness of their roles in today's multicultural classroom, it will be difficult to a get a good understanding of what is happening in their teaching and how and why that happens. 
Equipping Teachers to Work with Diverse Students

A wide range of research indicates that appropriate teacher education programs are helpful to develop teachers' ability to work with diverse students. However, the current programs seem far from satisfying in the achievement of this goal. According to the U.S. National Center for Education Statistics (2002), only 20\% of U.S. teachers reported feeling well prepared to meet the needs of students with limited English Proficiency or from different cultural backgrounds (Colombo, 2004)

In order to achieve the above goals, professional development for teachers must be designed to raise the cultural awareness and better prepare them to differentiate their instructional practice for different students. This may also be the key element in closing the achievement gap. To be effective, this training should be more than just disseminating information or instructional strategies, and must be systematic and continual (WhiteClark, 2005). As mentioned earlier, culturally responsive teaching is consistently indicated by research to be a promising approach to improving the academic achievement of diverse students. (Gay, 2001). Therefore, it should, and must, be a fundamental feature of teacher preparation and classroom practice (Gay \& Kirkland, 2003).

“A lack of cultural awareness and lack of specific of specific instruction in culturally relevant pedagogy have created classroom environments that fail to facilitate the success of culturally diverse students” (Bhargava et al., p. 19). In this regard, teacher education is a matter of developing "not only technical competence and solid knowledge of subject matter but also Sociocultural competence in working with the diversity students that characterize contemporary schooling” (Moll \& Arnot-Hopffer, 2005, p. 
244). It should start with acquiring an accurate knowledge base of the cultural dynamics of the different ethnic community and how interactions and relationships are negotiated. It should include specific strategies and skills about how to establish credibility and trust with different ethnic communities and parents, understand different cultural groups' interactional protocols, and translate educational jargon into language styles that a re meaningful for parents from other linguistic, social, and cultural backgrounds (Gay, 2001). 


\section{CHAPTER 3 METHODOLOGY}

This chapter describes the design and methodology of the study. This study was designed to investigate teacher candidates’ global mindedness and attitudes about teaching culturally and linguistically diverse students. Included are research questions, the research design, a description of the participants, the procedures, the research instruments, the limitations, strengths, and weaknesses of the design, and the protection of human subjects.

\section{Research Questions}

Study of teacher candidates’ intercultural awareness and disposition towards cultural diversity in the classroom was guided by the following questions.

1. How globally minded are teacher candidates?

2. What are teacher candidates' attitudes toward cultural diversity in the classroom?

3. Is there a relationship between teacher candidates' level of global mindedness and attitude toward cultural diversity in the classroom?

4. Is there a difference among teacher candidates' global mindedness and attitude towards diversity in the classroom based on the following demographics:
a. Age
b. Gender
c. Ethnicity
d. Teaching Experience
e. Course Work
f. International Travel/Study Abroad 


\section{g. Exposure to Domestic Diversity}

h. Religious Persuasion/Worldview

i. International Languages Spoken

\section{Research Design}

The design selected for this investigation is a cross-sectional design. Because the study proposes to investigate global mindedness and attitudes about teaching culturally and linguistically diverse learners between two groups of teacher candidates, comparing groups will be necessary to document the differences, if any, in global mindedness and attitudes towards diversity. Cross-sectional designs involve collecting data at one point in time from groups different in age and/or experience. These designs are not suitable for measuring change in an individual. However, differences between selected groups in a cross sectional study may represent changes that take place in a larger defined population (Wiersma, 2000).

Study Participants.

The population of interest in this study was two groups of teacher candidates enrolled in various fall programs at the data came from two groups of teacher candidates at a large mid-Atlantic university. One group entered the teacher education program with bachelor's degrees in various disciplines and will usually graduate with a master's degree in education after two years. The other group of teacher candidates has no bachelor's degrees and will usually graduate with a master's degree in education after five years of study. 
The Sampling Plan.

A convenience-sampling plan was employed in this study. This non-probability procedure is used in exploratory research where the researcher is interested in getting an inexpensive approximation of the truth, without incurring the cost or time required to select a random sample.

\section{Research Procedures}

Research Instruments

Two data collection instruments were employed in this study. The Global Mindedness Scale, and the Teacher Multicultural Attitude Survey. Participants also filled a brief demographic sheet that was attached to the questionnaires. Before data were collected, study participants were asked, in compliance with the IRB regulations, to sign the informed consent letter. Details about each instrument are presented below. Teacher multicultural attitude survey (TMAS). The investigator selected the "Teacher Multicultural Attitude Survey (TMAS)” to measure teacher candidates' level of intercultural awareness and attitudes towards cultural diversity. The TMAS was developed based upon a thorough review of the literature about multicultural sensitivity and competence and measures “teachers' awareness of, comfort with, and sensitivity to issues of cultural pluralism in the classroom” (Ponterotto, Baluch, Greig, \& Rivera, 1998, p. 1003). It comprises 20 closed-ended questions asking for degree of agreement on a 5point Likert scales (Lester \& Bishop, 2000) and is designed to allow the researcher to gather data on teacher candidates' beliefs and attitudes about multicultural education in a standardized way. It was normed on two samples of teachers and teacher education students. The alpha coefficient for TMAS was 0.86 and Test-retest reliability over a 
three-week period was 0.80 .

The Global Mindedness Scale. Hett (1993) developed the GMS. The Global-Mindedness Scale comprises of a 30 item Likert -type scale ranging across five choices from strongly disagree to strongly agree. The internal reliability for the GMS, using Cronbach’s coefficient alpha was .90 overall. Alpha subscales ranged from .70-.79 (Hett, 1993). A panel of four content judges established a Content Validity Index (CVI). The CVI for the overall tool was .88 (Hett, 1993).

The theoretical definition of global-mindedness and its dimensions in the scale is as follows:

- Global-Mindedness is a worldview in which ones sees oneself as connected to the world community and feels a sense of responsibility for its members. This commitment is reflected in an individual's attitudes, beliefs, and behaviors.

- Responsibility is a deep personal concern for people in all parts of the world, which surfaces as a sense of moral responsibility to try to improve conditions in some way.

- Cultural Pluralism is an appreciation of the diversity of cultures in the world and belief that all have something of value to offer. This is accompanied by taking pleasure in exploring and trying to understand other cultural frameworks.

- Efficacy is a belief that an individual's actions can make a difference and that involvement in national and international issues is important.

- Globalcentrism is thinking in terms of what is good for the global community, not just what will benefit one’s own country. A willingness to make judgments based on global rather than ethnocentric standards. 
- Interconnectedness is an awareness and appreciation of the interrelatedness of all peoples and nations which results in a sense of global belonging or kinship with the "human family" (Hett,1993).

Demographic Date Sheet. The researcher designed the demographic data sheet. The information gathered covered the participants' gender, age group, ethnicity, teaching experience, program of study, year in program, exposure to both domestic and international diversity, diversity training and courses taken, and religious persuasion or worldview. It was hoped that these pieces of demographic information would prove to be useful in analyzing the data.

\section{Data Collection}

Protection of human subjects. As with any research endeavor, the researcher must be sensitive to the ethical issues concerning the protection of human subjects. As this study dealt with the beliefs of teachers, keeping the data confidential was necessity. All the data was kept by the researcher. Anonymity for participants was assured. Study participants were instructed not to write their names on the research instrument. Approval of the study. The researcher applied to the University Human Subjects Committee and obtained permission to conduct the study. Permission was also sought and obtained from Dr. Ponterotto to use the data collection instruments. Data collection procedures. Data collection took take place in the fall 2007 semester. All study participants were presented with the research instrument(s). The instruments were administered in classrooms on the university campus at a time prearranged by the researcher and course instructors. The participants were given written and verbal directions to respond to the instrument(s) independently without consulting with each 
other. Alternatively, the instrument(s) were put online to reach students who will not be present in class at the time of administering. The researcher projected that online alternative will broaden the participant pool for rigorous analysis.

\section{Data Analysis}

Data obtained from the both the GMS and TMAS were analyzed using the Statistical Package for Social Sciences (SPSS). Data were sorted according to the groups of teacher candidates and mean scores and standard deviations for each group were calculated and presented in tables. In order to assess the significance of any mean differences among groups, univariate t-tests were employed to analyze research questions one and two. To determine the significant mean differences between specific groups Tukey's HSD test was employed (Huck, 2008). For research question three bivariate correlational analysis was used to determine the relationship between teacher candidates' global mindedness and attitudes towards diversity in the classroom. A multivariate analysis of variance (MANOVA) was used to analyze research question four. 


\section{CHAPTER 4 PRESENTATION AND ANALYSIS OF DATA}

In Chapter 4, the results of the research are presented in a descriptive format as with tables. The results of chapter 4 are divided into three sections (a) demographic

findings, (b) investigation of assumptions as relates to inferential analysis, and (c) tests of hypotheses. The chapter concludes with a summary of the results. SPSS v15.0 was used for all descriptive and inferential analyses.

This cross-sectional causal-comparative study was designed to investigate global mindedness and attitudes about teaching culturally and linguistically diverse students between two groups of teacher candidates. The study was guided by the following research questions:

1. How globally minded are teacher candidates?

2. What are teacher candidates' attitudes toward cultural diversity in the classroom?

3. Is there a relationship between teacher candidates' level of global mindedness and attitude toward cultural diversity in the classroom?

4. Is there a difference among teacher candidates' global mindedness and attitude towards diversity in the classroom based on the following demographics:
a. Age
b. Gender
c. Ethnicity
d. Teaching Experience
e. Course Work 
f. International Travel/Study Abroad

g. Exposure to Domestic Diversity

h. Religious Persuasion/Worldview

i. International Languages Spoken

Population and Demographic Analysis

The dataset used in this study included a convenience sample of 102 teachers and teacher candidates enrolled in various fall programs at a large Mid Atlantic land grant university in the $S$.

Two data collection instruments were employed in this study (a) The Global Mindedness Scale (GMS), and (b) The Teacher Multicultural Attitude Survey (TMAS).

Participants also completed a brief demographic sheet that was attached to the questionnaires. Table 1 includes demographic information for the sample. 
Table 1

Frequency Statistics for Demographic Study Variables (N=102)

\begin{tabular}{|c|c|c|}
\hline Variable & Frequency & Percentage \\
\hline \multicolumn{3}{|l|}{ Gender } \\
\hline Male & 29 & 28.4 \\
\hline Female & 73 & 71.6 \\
\hline \multicolumn{3}{|l|}{ Age (in years) } \\
\hline 21 & 1 & 1.0 \\
\hline 22 & 35 & 34.3 \\
\hline 23 & 36 & 35.3 \\
\hline 24 & 11 & 10.8 \\
\hline 25 & 5 & 4.9 \\
\hline 26 & 2 & 2.0 \\
\hline 27 & 3 & 2.9 \\
\hline 28 & 2 & 2.0 \\
\hline 29 & 3 & 2.9 \\
\hline 30 & 1 & 1.0 \\
\hline 32 & 1 & 1.0 \\
\hline 35 & 1 & 1.0 \\
\hline 39 & 1 & 1.0 \\
\hline
\end{tabular}


Table 1 (Contd.)

Frequency Statistics for Demographic Study Variables (N=102)

Variable

Frequency

Percentage

Ethnicity

African-American

1

1.0

Caucasian

100

98.0

Asian

1

1.0

Program type

Post-baccalaureate

51

50.0

5-year

51

50.0

Teaching experience

Yes

57

No

45

44.1

International exposure

Yes

45

44.1

No

57

Worldview

Christian

79

77.5

Jewish

1

1.0

Spiritual

4

3.9

Other

18

17.6 
Table 1 (Contd.)

Frequency Statistics for Demographic Study Variables (N=102)

Variable

Frequency

Percentage

Relevant courses

3 or more

50

49.0

Less than 2

52

51.0

Languages spoken

English only

58

56.9

English and another

44

43.1

Perceived exposure to domestic diversity

Some experience

77.5

No experience

23

22.5

Of the 102 participants (51 or 50\%) were post bachelor teacher candidates and another (51 or 50\%) were 5-year teacher candidates. Overall, the participants were predominantly female (73 or 71.6\%). Most of the participants were between the ages of 22-24 years (82 or 80.4\%). One hundred participants (98.0\%) were Caucasian. Seventynine (77.5\%) held a Christian worldview. Seventy-nine (77.5\%) claimed some experience with the variable "Perceived Exposure to Diversity" while only 45 (44.1\%) claimed some international experience. Fifty-one (55.9\%) have had some teaching experience. Fifty (49\%) have taken three or more course that dealt with global and diversity issues. Fiftyeight (56.9\%) spoke only English. 
Since the sample was overwhelmingly Caucasian and Christian, the groups of Ethnicity and Worldview were consequently removed from inferential analysis as relates to research question 4 .

\author{
Inferential Analysis
}

\title{
Instrumentation
}

Two survey instruments were utilized in this study: (a) The Global Mindedness Scale (GMS), a 30-item Likert type scale which assesses participant's responses on six distinct dimensions of global mindedness; and (b) The Teacher Multicultural Attitude Survey (TMAS), a 20-item Likert type scale which measures teacher candidates' level of intercultural awareness and attitudes towards cultural diversity.

For this study, seven latent variable constructs were derived from the two survey instruments. Global mindedness assessment included six variable constructs from the GMS. The first construct, (a) Global Mindedness (GMS Score), was compiled from the total summed scores on the Global Mindedness Scale. Five additional constructs derived from various item-responses on the GMS were (b) Responsibility, (c) Cultural Pluralism, (d) Efficacy, (e) Globalcentrism, and (f) Interconnectedness. An additional latent variable construct of (g) Multicultural Attitude (TMAS Score), was derived from the summed scores on the TMAS instrument. Table 2 lists the latent variable constructs used for inferential analysis as well as each construct’s associated survey item responses. 
Table 2

Latent Variable constructs for Study, and Associated Response Item Numbers, According to Survey Instrument $(N=102)$

Variable

Associated response item numbers

GMS

Global mindedness

Response items 21 - 50 inclusive (reverse score items 24, 25, 29, 30, $36,41,45,47,49)$

Responsibility

22, 27, 32, 38, 43, 46, 50

Cultural pluralism

$21,23,28,33,34,39,44,47$

Efficacy

24, 29, 35, 40, 48

Globalcentrism

25, 30, 36, 41, 49

Interconnectedness

26, 31, 37, 42, 45

TMAS

Multicultural attitude

Response items 1 - 20 inclusive (reverse score items 3, 6, 12, 15, 16, 19,20 )

Note. GMS = Global Mindedness Scale; TMAS = Teacher Multicultural Attitude Survey.

Assumptions for Data Analysis

Inferential analysis included univariate (t-tests), bivariate (correlational) and multivariate (MANOVA) techniques. Assumptions differ according to the techniques used. Therefore, assumptions will be presented in the following order: (a) Assumptions required of all inferential analyses performed on the dataset, (b) additional assumptions 
required for univariate and bivariate techniques, and (c) multivariate analysis assumptions.

Assumptions as Related to Inferential Analyses Performed on the Dataset.

General to all inferential analyses included in this study are the assumptions of (a) no missing data, (b) absence of outliers, and (c) Normality of distribution.

No records were missing data.

Outliers in a dataset have the potential to distort results of an inferential analysis. A check of boxplots for the seven latent variable constructs (as defined in Table 2) was performed to visually inspect for outliers. The boxplots indicated 14 (13.7\%) possible univariate outliers for five of the constructs: (a) GMS Score = 2 outliers, (b) Responsibility = 1 outlier, (c) Cultural Pluralism $=3$ outliers, (d) Global Centrism $=7$ outliers, and (e) Interconnectedness = 1 outlier. None of the outliers appeared extreme, and all outlier values were within acceptable score ranges on each of the constructs. Scores were standardized to check for extreme values (+/- 3.3). No extreme outliers were indicated on the standardized scores. Since all visual outliers were within acceptable ranges and standardization did not indicate extreme outlying values, the outlier assumption was not violated. All outliers were retained for analysis.

Normality for the seven latent variable constructs was investigated with SPSS EXPLORE. The Kolmogorov-Smirnov test for normality indicated normal distributions on three variables: (a) GMS Score, (b) Responsibility, and (c) TMAS Score. A check of histograms for the remaining four variable constructs did not show strong deviance from normality. The construct of Cultural Pluralism indicated a slight negative skew, but the mean $(M=31.66)$ and median $(M d n=32)$ were close in value. The construct of Efficacy 
appeared normal in the histogram and the mean $(M=18.94)$ and median $(M d n=19)$ were also very close in value. The histogram for the construct of Global Centrism tended left of normal, but the mean $(M=16.23)$ and median $(M d n=16)$ were close in value. The histogram for the construct of Global Centrism tended right of normal, but the mean ( $M=$ 18.32) and median $(M d n=19)$ were close in value.

Since the means and medians were close in value for the four variable constructs that did not test normal, it was further confirmed that outliers were not impacting the dataset, and the assumption of normality was not considered violated. All records were retained for analysis, and parametric tests were used on the constructs during inferential analysis. Table 3 shows the seven variable constructs used during inferential analysis and their associated measures of central tendency. 
Table 3

Descriptive Statistics for Summed Latent Variable Constructs as Relates to Inferential Hypotheses $(N=102)$

\begin{tabular}{lccccr}
\hline Variable & $M$ & SE $M$ & SD & $\begin{array}{c}\text { Possible } \\
\text { Range }\end{array}$ & $\begin{array}{c}\text { Sample } \\
\text { Range }\end{array}$ \\
\hline GMS (90) & 100.63 & 1.30 & 13.13 & $30-150$ & $68-147$ \\
Responsibility (21) & 25.48 & 0.38 & 3.80 & $7-35$ & $15-35$ \\
Cultural pluralism (24) & 31.66 & 0.39 & 3.90 & $8-40$ & $20-39$ \\
Efficacy (15) & 18.94 & 0.27 & 2.68 & $5-25$ & $11-25$ \\
Global centrism (15) & 16.23 & 0.29 & 2.91 & $5-25$ & $10-25$ \\
Interconnectedness (15) & 18.32 & 0.31 & 3.07 & $5-25$ & $8-25$ \\
TMAS (60) & 77.69 & 0.80 & 8.08 & $20-100$ & $58-96$ \\
\hline
\end{tabular}

Note. GMS = Global Mindedness Scale; TMAS = Teacher Multicultural Attitude Survey. Values in parentheses indicate mean score values for the given construct scale.

Table 3 defines the measures of central tendency as relates to the latent variable constructs derived from the summed scales of GMS (GMS Score) and TMAS (TMAS Score), as well as descriptive analysis of latent variable constructs of the five GMS subscales of (a) Responsibility, (b) Cultural Pluralism, (c) Efficacy, (d) Globalcentrism, and (e) Interconnectedness. constructs, including means, standard errors of the means, standard deviations, possible score ranges, and the sample range of scores. Numbers in parentheses in are the mean range values according to the construct scales. 
Additional Assumptions required for Univariate and Bivariate Inferential Analysis

Additional assumptions of (a) linearity, (b) homoscedasticity, and (c)

homogeneity of variances were checked visually. Assumptions of linearity between the seven variable constructs and homoscedasticity, requirements for correlational analysis, were checked with visual inspection of scatterplots of the data. The assumptions of linearity and homoscedasticity were not violated. Homogeneity of variances was checked during independent samples t-test analysis using Levene’s Test of Equal Variances. The assumption was not violated.

Assumptions as Relates to Multivariate Analysis of Variance (MANOVA) Multivariate analysis of variance (MANOVA) was used to address Research Question 4. MANOVA requires assumptions related to (a) sample size, (b) multivariate outliers and normality, (c) multicollinearity and singularity, and (d) homogeneity of variance-covariance structures.

MANOVA requires the count of cases in each cell to be greater than the number of dependent variables included in the analysis. A factorial MANOVA was initially attempted with the six independent variables from Research Question 4 and the seven latent variable constructs as defined in Table 3. The cell counts were too small to meet the cell count assumption, therefore it was determined that six separate one-way MANOVA analyses would be performed. Additionally, instead of using all seven latent variable constructs as dependent variables in the MANOVA's, the construct of GMS Score was removed from analysis because the five latent variable sub-groups defined this variable. Removing the dependent variable of GMS Score allowed the individual cell counts to be lower and helped to avoid singularity in analysis. With these revisions of 
process, the assumptions of sample size and absence of singularity were met.

Multivariate outliers and multivariate normality were investigated for the dataset. Mahalanobis distances were calculated for all cases using SPSS Regression. The maximum Mahalanobis distance value was 22.41. This number was used as a test-statistic and checked against a critical value to determine if the data deviated from normality and if multivariate outliers were present in the dataset. The test statistic was checked against a chi-square table and did not exceed the critical value, $\chi^{2}(6, N=102)=22.46, p>.001$. The assumptions of multivariate normality and absence of multivariate outliers were met. Multicollinearity was checked by running correlations on the six dependent variables used in MANOVA analysis. The assumption of absence of multicollinearity was met.

Homogeneity of variance-covariance structures was checked with the Box’s M Test of Equality of Covariance Matrices, which was given in the SPSS output for each of the six one-way MANOVA's. The significance value for rejection of the assumption of homogeneity of variance-covariance structures was set at $p<.001$. The assumption of homogeneity of the variance-covariance matrices was not violated. Reliability

Cronbach's coefficient alpha was used to check the internal consistency reliability of the seven variable constructs with the data obtained in this study. Cronbach's alpha values for each variable construct are as follows: (a) GMS Score = .895; (b) Responsibility $=.717$; (c) Cultural Pluralism $=.742 ;$ (d) Efficacy $=.617$; (e) Globalcentrism $=.602$; (f) Interconnectedness $=.676$; and (g) TMAS Score $=.824$. A Cronbach's alpha value of .70 or above is considered "acceptable.” All 
constructs were reliable for the dataset used in this study with the exception of Efficacy, Globalcentrism, and Interconnectedness. However, the Cronbach's alpha scores were not far below the threshold level of .70, removing any of the item-responses from an individual construct would not improve the coefficients, and the GMS Score had a "very good” coefficient of .895. Additionally, the scales have been utilized in previous research and possess good test/re-test reliability. Therefore, it was determined that the three lower scoring constructs would be retained for analysis as-is without revisions such as removal of construct item-responses.

\section{Hypothesis Testing}

Statistical hypotheses for inferential analysis as relates to the research questions are as follows:

\section{Research Question 1:}

How globally minded are teacher candidates?

Null Hypothesis 1: There is not a statistically significant difference in mean scores on any of the six latent variable constructs between the two groups of (a) teacher candidates who had a bachelor's degree before beginning the education program, vs. (b) teacher candidates who began the education program before obtaining a bachelor's degree.

Alternative Hypothesis 1: There is a statistically significant difference in mean scores on at least one of the six latent variable constructs between the two groups of (a) teacher candidates who had a bachelor's degree before beginning the education program, vs. (b) teacher candidates who began the education program before obtaining a bachelor's degree. Table 4 reflects summary of results for Hypothesis 1 
Table 4

Summary of Results for Independent Samples t-tests as Relates to Hypothesis 1, Comparison of Teacher Candidates who Possessed a Bachelor's Degree $(n=51)$ vs.

Teacher Candidates Who Had Not Previously Obtained a Bachelor's Degree $(n=51)$, $(N=102)$

\begin{tabular}{|c|c|c|c|c|c|}
\hline $\begin{array}{l}\text { Variable } \\
\text { Supported? }\end{array}$ & $\begin{array}{l}\text { Mean Score } \\
\text { B.A./B.S. }\end{array}$ & $\begin{array}{l}\text { Mean Score } \\
\text { No B.A./B.S }\end{array}$ & Diff & $t$ & Sig. \\
\hline $\begin{array}{l}\text { GMS Score } \\
\text { Yes }\end{array}$ & 116.08 & 105.18 & 10.90 & 4.59 & $\mathrm{p}<.0005$ \\
\hline $\begin{array}{l}\text { Responsibility } \\
\text { Yes }\end{array}$ & 26.69 & 24.27 & 2.42 & 3.37 & $\mathrm{p}<.0005$ \\
\hline $\begin{array}{l}\text { Cultural pluralism } \\
\text { Yes }\end{array}$ & 33.27 & 30.04 & 3.23 & 4.59 & $\mathrm{p}<.0005$ \\
\hline $\begin{array}{l}\text { Efficacy } \\
\text { Yes }\end{array}$ & 19.94 & 17.94 & 2.00 & 4.04 & $\mathrm{p}<.0005$ \\
\hline $\begin{array}{l}\text { Global centrism } \\
\text { No }\end{array}$ & 16.76 & 15.69 & 1.07 & 1.46 & $\mathrm{p}=.061$ \\
\hline $\begin{array}{l}\text { Interconnectedness } \\
\text { Yes }\end{array}$ & 19.41 & 17.24 & 2.17 & 3.81 & $\mathrm{p}<.0005$ \\
\hline
\end{tabular}

Note. GMS = Global Mindedness Scale. The other latent variables are subscales of the GMS. Diff = Difference in Mean Scores; Sig. = Significance via p-value.

Inferential Analysis as relates to Hypothesis 1

Independent samples t-tests were performed to investigate mean differences between the teacher candidate populations of the two teacher groups (previous bachelor's degree vs. no previous bachelor's degree). Six independent samples t-tests were performed to assess differences in the two groups on each of the latent variable constructs. To safeguard against inflated Type I error (observing significance that truly is not in the data) the Bonferroni correction was used to adjust the p-threshold for rejection of the null hypothesis from .05 to $.05 / 7=.007$. Rejection of the null hypothesis was 
determined for all t-tests when the p-value was less than or equal to .007. Table 5 shows the results for the independent samples t-tests for the two teacher candidate groups. There was a significant effect for GMS Score $t(100)=4.59, p<.0005$, with the teacher candidates who already possessed a bachelor's degree receiving higher scores than those who had not previously obtained a bachelor's degree.

There was a significant effect for Responsibility $t(100)=3.37, p=.001$, with the teacher candidates who already possessed a bachelor's degree receiving higher scores than those who had not previously obtained a bachelor's degree. There was a significant effect for Cultural Pluralism $t(100)=4.59, p<.0005$, with the teacher candidates who already possessed a bachelor's degree receiving higher scores than those who had not previously obtained a bachelor's degree. There was a significant effect for Efficacy $t$ $(100)=4.04, p<.0005$, with the teacher candidates who already possessed a bachelor's degree receiving higher scores than those who had not previously obtained a bachelor's degree. There was a significant effect for Interconnectedness $t(100)=3.81, p<.0005$, with the teacher candidates who already possessed a bachelor's degree receiving higher scores than those who had not previously obtained a bachelor's degree.

Statistical significance was indicated on five of the six variable constructs, therefore Null Hypothesis 2 is rejected; there is sufficient evidence to indicate that the two groups (previous bachelor's degree vs. no previous bachelor's degree) differ on at least one of the associated latent variable constructs.

Reviewing the mean scores of the two groups in Table 5, it is evident that teacher candidates with a prior bachelor's degree scored significantly higher scores than teacher candidates without a bachelor's degree. Thus, it can be concluded that teacher candidates 
with a prior bachelor's degree have a more positive orientation toward global issues. Research Question 2:

What is teacher candidates' attitude toward cultural diversity in the classroom?

Null Hypothesis 2: There is not a statistically significant difference in mean scores between the two groups of (a) teacher candidates who had a bachelor's degree before beginning the education program, vs. (b) teacher candidates who began the education program before obtaining a bachelor's degree.

Alternative Hypothesis 2: There is a statistically significant difference in mean scores between the two groups of (a) teacher candidates who had a bachelor's degree before beginning the education program, vs. (b) teacher candidates who began the education program before obtaining a bachelor's degree. Table 5 shows summary of results for hypothesis 2

Table 5

Summary of Results for Independent Samples t-tests as Relates to Hypothesis 2, Comparison of Teacher Candidates who Possessed a Bachelor's Degree $(n=51)$ vs. Teacher Candidates Who Had Not Previously Obtained a Bachelor's Degree $(n=51)$, $(N=102)$

\begin{tabular}{llllll}
\hline Variable & Mean Score & Mean Score & Diff & $t$ & Sig. \\
Supported? & B.A./B.S. & No B.A./B.S & & & \\
& & & &
\end{tabular}

$\begin{array}{llllll}\text { TMAS score } & 80.84 & 74.53 & 6.31 & 4.27 & \mathrm{p}<.0005 \\ \text { Yes } & & & & & \end{array}$

Note. TMAS = Teacher Multicultural Attitude Survey; Diff = Difference in Mean Scores; Sig. $=$ Significance via -value. 
Inferential Analysis as relates to Hypothesis 2

Independent samples t-tests were performed to investigate mean differences between the teacher candidate populations of the two teacher groups (previous bachelor's degree vs. no previous bachelor's degree). There was a significant effect for TMAS Score $t(100)=4.27, p<.0005$, with the teacher candidates who already possessed a bachelor's degree receiving higher scores than those who had not previously obtained a bachelor's degree.

Statistical significance was indicated between the mean score therefore Null Hypothesis 2 is rejected; there is sufficient evidence to indicate that the two groups (previous bachelor's degree vs. no previous bachelor’s degree) differ significantly. Reviewing the mean scores of the two groups in Table 5, it is evident that teacher candidates with a prior bachelor's degree scored significantly higher scores than teacher candidates without a bachelor's degree. Thus, it can be concluded that teacher candidates with a prior bachelor's degree have a more positive orientation towards diversity issues in the classroom.

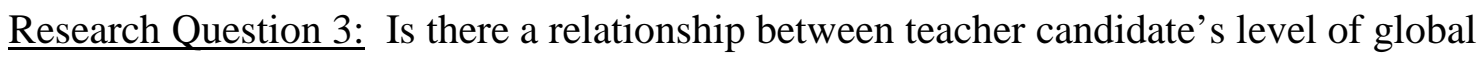
mindedness and attitude toward cultural diversity in the classroom?

Null Hypothesis 3: There is not a statistically significant correlation between the summed scores of the two survey instruments (a) The Global Mindedness Scale (GMS Score), and (b) The Teacher Multicultural Attitude Survey (TMAS).

Alternative Hypothesis 3: There is a statistically significant correlation between the summed scores of the two survey instruments (a) The Global Mindedness Scale 
(GMS Score), and (b) The Teacher Multicultural Attitude Survey (TMAS).

Inferential Analysis as Relates to Hypothesis 3

Pearson's product moment correlation was performed to assess the relationship between the summed scores of the two variables (a) GMS Score, and (b) TMAS. The correlation between the two variables was strong, positive, and significant, $\mathrm{r}(100)=.628$, $\mathrm{p}<.01$. The positive correlation suggests that when scores on one of the variables increases or decreases, the values on the other variable move in a like manner.

Reject Null Hypothesis 3, there is sufficient evidence to indicate a relationship between the two variables of GMS Score and TMAS.

\section{Research Question 4:}

Is there a difference among teacher candidates' global mindedness and attitude towards diversity in the classroom based on the following demographics of (a) age, (b) gender, (c) course work, (d) international travel/study abroad, (e) exposure to domestic diversity, and (f) international languages spoken.

Null Hypothesis 4a: There are not any statistically significant correlations between the variable of age and the summed scores on the six latent variable constructs of (a) Responsibility, (b) Cultural Pluralism, (c) Efficacy, (d) Global Centrism, (e) Interconnectedness, and (f) TMAS Score.

Alternative Hypothesis 4a: There is at least one statistically significant correlation between the variable of age and the summed scores on the six latent variable constructs of (a) Responsibility, (b) Cultural Pluralism, (c) Efficacy, (d) Global Centrism, (e) Interconnectedness, and (f) TMAS Score.

Null Hypothesis 4b: There is not a statistically significant difference in the mean 
scores of male and female teacher candidates in terms of the six latent variable constructs of (a) Responsibility, (b) Cultural Pluralism, (c) Efficacy, (d) Global Centrism, (e) Interconnectedness, and (f) TMAS Score.

Alternative Hypothesis 4b: There is at least one statistically significant difference in the mean scores of male and female teacher candidates in terms of the six latent variable constructs of (a) Responsibility, (b) Cultural Pluralism, (c) Efficacy, (d) Global Centrism, (e) Interconnectedness, and (f) TMAS Score.

Null Hypothesis 4c: There is not a statistically significant difference in the mean scores of teacher candidates with teaching experience vs. teacher candidates without teaching experience in terms of the six latent variable constructs of (a) Responsibility, (b) Cultural Pluralism, (c) Efficacy, (d) Global Centrism, (e) Interconnectedness, and (f) TMAS Score.

Alternative Hypothesis 4c: There is at least one statistically significant difference in the mean scores of teacher candidates with teaching experience vs. teacher candidates without teaching experience in terms of the six latent variable constructs of (a) Responsibility, (b) Cultural Pluralism, (c) Efficacy, (d) Global Centrism, (e) Interconnectedness, and (f) TMAS Score.

Null Hypothesis 4d: There is not a statistically significant difference in the mean scores of teacher candidates with 3 or more courses in global/multicultural issues vs. teacher candidates with less than 3 courses in global/multicultural issues in terms of the six latent variable constructs of (a) Responsibility, (b) Cultural Pluralism, (c) Efficacy, (d) Global Centrism, (e) Interconnectedness, and (f) TMAS Score.

Alternative Hypothesis 4d: There at least one statistically significant difference in 
the mean scores of teacher candidates with 3 or more courses in global/multicultural issues vs. teacher candidates with less than 3 courses in global/multicultural issues in terms of the six latent variable constructs of (a) Responsibility, (b) Cultural Pluralism, (c) Efficacy, (d) Global Centrism, (e) Interconnectedness, and (f) TMAS Score.

Null Hypothesis 4e: There is not a statistically significant difference in the mean scores between teacher candidates who have traveled abroad and those who have not traveled abroad in terms of the six latent variable constructs of (a) Responsibility, (b) Cultural Pluralism, (c) Efficacy, (d) Global Centrism, (e) Interconnectedness, and (f) TMAS Score.

Alternative Hypothesis 4e: There is at least one statistically significant difference in the mean scores between teacher candidates who have traveled abroad and those who have not traveled abroad in terms of the six latent variable constructs of (a) Responsibility, (b) Cultural Pluralism, (c) Efficacy, (d) Global Centrism, (e) Interconnectedness, and (f) TMAS Score.

Null Hypothesis 4f: There is not a statistically significant difference in the mean scores between teacher candidates who profess exposure to domestic diversity vs. those who claim to not have exposure to domestic diversity in terms of the six latent variable constructs of (a) Responsibility, (b) Cultural Pluralism, (c) Efficacy, (d) Global Centrism, (e) Interconnectedness, and (f) TMAS Score.

Alternative Hypothesis 4f: There is at least one statistically significant difference in the mean scores between teacher candidates who profess exposure to domestic diversity vs. those who claim to not have exposure to domestic diversity in terms of the six latent variable constructs of (a) Responsibility, (b) Cultural Pluralism, (c) Efficacy, 
(d) Global Centrism, (e) Interconnectedness, and (f) TMAS Score.

Null Hypothesis 4g: There is not a statistically significant difference in the mean scores between teacher candidates who speak more than one language vs. those who speak one language in terms of the six latent variable constructs of (a) Responsibility, (b) Cultural Pluralism, (c) Efficacy, (d) Global Centrism, (e) Interconnectedness, and (f) TMAS Score.

Alternative Hypothesis 4g: There is at least one statistically significant difference in the mean scores between teacher candidates who speak more than one language vs. those who speak one language in terms of the six latent variable constructs of (a) Responsibility, (b) Cultural Pluralism, (c) Efficacy, (d) Global Centrism, (e) Interconnectedness, and (f) TMAS Score. Table 6 shows the summary results for hypothesis 4 . 
Table 6

Summary of Significant Results for Pearson's Product Moment Correlation (Hypothesis 4a) and One-Way MANOVA Analyses (Hypotheses 4b-4g) as Relates to Hypothesis 4, Comparison of Sample Independent Demographic Variables with Study Latent Variable Constructs $(N=102)$

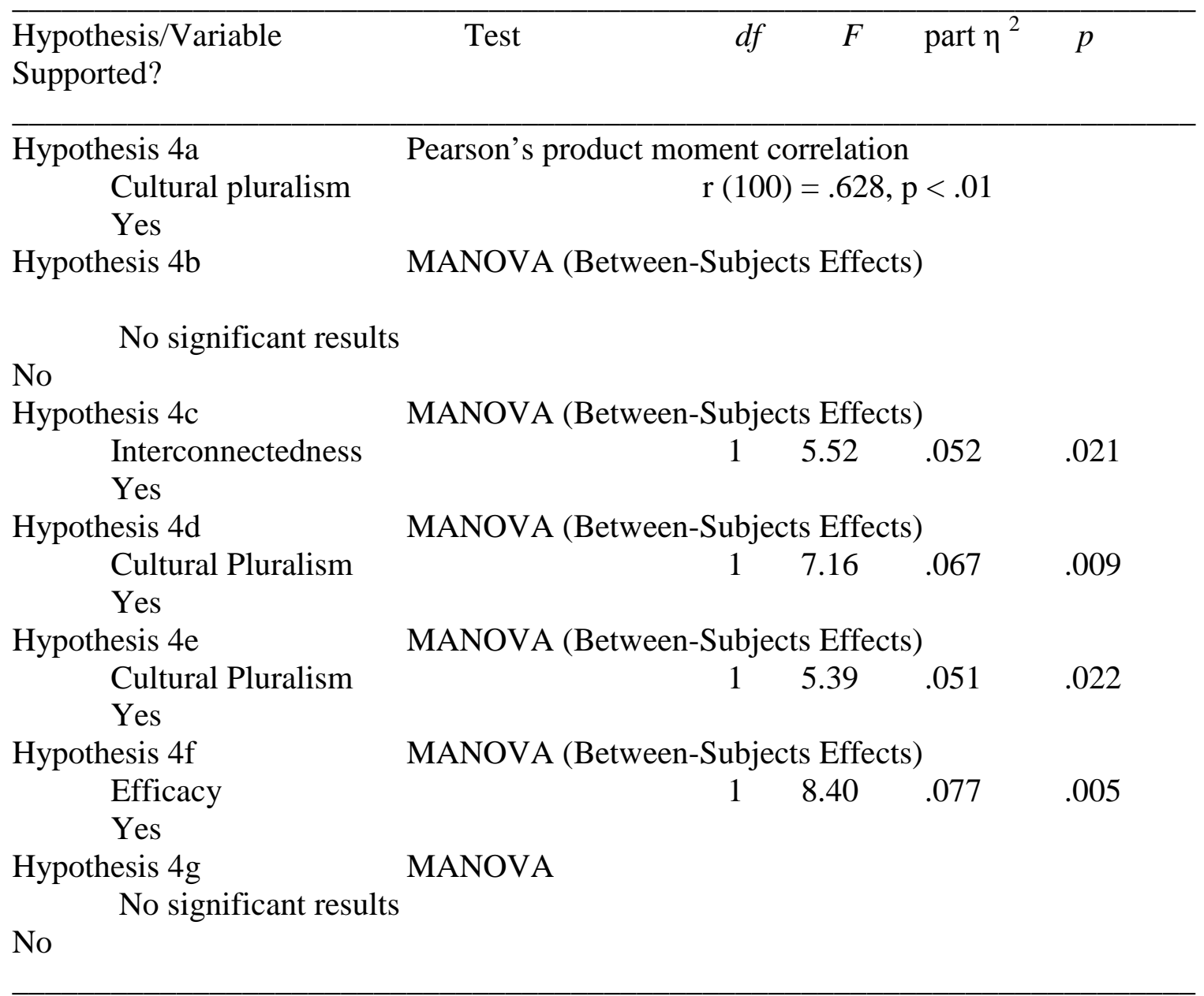

Inferential Analysis as Relates to Hypothesis 4

A summary of results for Hypothesis 4 are listed in Table 6.

Null Hypothesis 4a: There are not any statistically significant correlations between the variable of age and the summed scores on the six latent variable constructs of (a) Responsibility, (b) Cultural Pluralism, (c) Efficacy, (d) Global Centrism, (e) Interconnectedness, and (f) TMAS Score. 
Alternative Hypothesis 4a: There is at least one statistically significant correlation between the variable of age and the summed scores on the six latent variable constructs of (a) Responsibility, (b) Cultural Pluralism, (c) Efficacy, (d) Global Centrism, (e) Interconnectedness, and (f) TMAS Score.

Pearson's product moment correlation was performed to assess the relationship between the continuous demographic variable of age and the summed scores summed scores on the six latent variable constructs of (a) Responsibility, (b) Cultural Pluralism, (c) Efficacy, (d) Global Centrism, (e) Interconnectedness, and (f) TMAS Score. Only one correlation was significant. The correlation between the two variables of Age and Cultural Pluralism was small, positive, and significant, $r(100)=.240, p<.05$. The positive correlation suggests that when a teacher candidate's age increases or decreases, summed scores on the variable construct of Cultural Pluralism move in a like manner.

Null Hypothesis 4a is rejected because there is sufficient evidence to indicate a correlation between the variables of Age and Cultural Pluralism.

Null Hypothesis 4b: There is not a statistically significant difference in the mean scores of male and female teacher candidates in terms of the six latent variable constructs of (a) Responsibility, (b) Cultural Pluralism, (c) Efficacy, (d) Global Centrism, (e) Interconnectedness, and (f) TMAS Score.

Alternative Hypothesis 4b: There is at least one statistically significant difference in the mean scores of male and female teacher candidates in terms of the six latent variable constructs of (a) Responsibility, (b) Cultural Pluralism, (c) Efficacy, (d) Global Centrism, (e) Interconnectedness, and (f) TMAS Score.

A one-way between groups multivariate analysis of variance was performed to 
investigate gender differences in teacher candidates’ global mindedness and attitudes about teaching culturally and linguistically diverse students. Six dependent variables were used: (a) Responsibility, (b) Cultural Pluralism, (c) Efficacy, (d) Global Centrism, (e) Interconnectedness, and (f) TMAS Score. Preliminary assumption testing was conducted to check for normality, linearity, outliers (univariate and multivariate) homogeneity of variance-covariance matrices, and multicollinearity. There were no violations of these assumptions. Due to multiple testing of the dependent variables using six independent variables in six different one-way MANOVA's, the level for significance was adjusted to .0225 . This adjustment allowed for protection against Type I error while keeping the experiment-wise error rate below .10. There was not a statistically significant difference between males and females on the combined dependent variables. There were also no statistically significant results when each of the dependent variables was considered separately.

Do not reject Null Hypothesis $4 \mathrm{~b}$ because there is insufficient evidence to indicate statistically significances in the mean scores of male vs. female teacher candidates in terms of any of the six dependent variable constructs.

Null Hypothesis 4c: There is not a statistically significant difference in the mean scores of teacher candidates with teaching experience vs. teacher candidates without teaching experience in terms of the six latent variable constructs of (a) Responsibility, (b) Cultural Pluralism, (c) Efficacy, (d) Global Centrism, (e) Interconnectedness, and (f) TMAS Score.

Alternative Hypothesis 4c: There is at least one statistically significant difference in the mean scores of teacher candidates with teaching experience vs. teacher candidates 
without teaching experience in terms of the six latent variable constructs of (a)

Responsibility, (b) Cultural Pluralism, (c) Efficacy, (d) Global Centrism, (e) Interconnectedness, and (f) TMAS Score.

A one-way between groups multivariate analysis of variance was performed to investigate differences in teacher candidates' global mindedness and attitudes about teaching culturally and linguistically diverse students between the two groups of candidates with teaching experience vs. candidates without teaching experience. Six dependent variables were used: (a) Responsibility, (b) Cultural Pluralism, (c) Efficacy, (d) Global Centrism, (e) Interconnectedness, and (f) TMAS Score. Preliminary assumption testing was conducted to check for normality, linearity, outliers (univariate and multivariate) homogeneity of variance-covariance matrices, and multicollinearity. There were no violations of these assumptions. Due to multiple testing of the dependent variables using six independent variables in six different one-way MANOVA's, the level for significance was adjusted to .0225 . This adjustment allowed for protection against Type I error while keeping the experiment-wise error rate below .10. There was not a statistically significant difference between the two groups of candidates with teaching experience vs. candidates without teaching experience on the combined dependent variables. When considered separately, one dependent variable, Interconnectedness, indicated significance, $F(1,100)=5.52, p=.021$, partial eta squared $=.052$. A review of the mean scores for the two groups indicated that teacher candidates without teaching experience reported higher levels of Interconnectedness $(M=19.11, S D=2.66)$ than candidates with teaching experience $(M=17.70, S D=3.25)$.

Reject Null Hypothesis 4c because there is sufficient evidence to indicate that the 
two groups of candidates with teaching experience vs. candidates without teaching experience significantly differ in their mean scores on the dependent variable of Interconnectedness.

Null Hypothesis 4d: There is not a statistically significant difference in the mean scores of teacher candidates with 3 or more courses in global/multicultural issues vs. teacher candidates with less than 3 courses in global/multicultural issues in terms of the six latent variable constructs of (a) Responsibility, (b) Cultural Pluralism, (c) Efficacy, (d) Global Centrism, (e) Interconnectedness, and (f) TMAS Score.

Alternative Hypothesis 4d: There is at least one statistically significant difference in the mean scores of teacher candidates with 3 or more courses in global/multicultural issues vs. teacher candidates with less than 3 courses in global/multicultural issues in terms of the six latent variable constructs of (a) Responsibility, (b) Cultural Pluralism, (c) Efficacy, (d) Global Centrism, (e) Interconnectedness, and (f) TMAS Score.

A one-way between groups multivariate analysis of variance was performed to investigate differences in teacher candidates’ global mindedness and attitudes about teaching culturally and linguistically diverse students between the two groups of candidates with 3 or more courses in global/multicultural issues vs. teacher candidates with less than 3 courses in global/multicultural issues. Six dependent variables were used: (a) Responsibility, (b) Cultural Pluralism, (c) Efficacy, (d) Global Centrism, (e) Interconnectedness, and (f) TMAS Score. Preliminary assumption testing was conducted to check for normality, linearity, outliers (univariate and multivariate) homogeneity of variance-covariance matrices, and multicollinearity. There were no violations of these assumptions. Due to multiple testing of the dependent variables using six independent 
variables in six different one-way MANOVA's, the level for significance was adjusted to .0225. This adjustment allowed for protection against Type I error while keeping the experiment-wise error rate below .10. There was not a statistically significant difference between the two groups of teacher candidates with 3 or more courses in global/multicultural issues vs. teacher candidates with less than 3 courses in global/multicultural issues on the combined dependent variables. When considered separately, one dependent variable, Cultural Pluralism, indicated significance, $F(1,100)$ $=7.16, p=.009$, partial eta squared $=.067$. A review of the mean scores for the two groups indicated that teacher candidates with 3 or more courses in global/multicultural issues reported higher levels of Cultural Pluralism $(M=32.68, S D=3.75)$ than candidates with less than 3 courses $(M=30.67, S D=3.81)$.

Reject Null Hypothesis 4d because there is sufficient evidence to indicate that the two groups of candidates with 3 or more courses in global/multicultural issues vs. teacher candidates with less than 3 courses in global/multicultural issues significantly differ in their mean scores on the dependent variable of Cultural Pluralism.

Null Hypothesis 4e: There is not a statistically significant difference in the mean scores between teacher candidates who have traveled abroad and those who have not traveled abroad in terms of the six latent variable constructs of (a) Responsibility, (b) Cultural Pluralism, (c) Efficacy, (d) Global Centrism, (e) Interconnectedness, and (f) TMAS Score.

Alternative Hypothesis 4e: There is at least one statistically significant difference in the mean scores between teacher candidates who have traveled abroad and those who have not traveled abroad in terms of the six latent variable constructs of (a) 
Responsibility, (b) Cultural Pluralism, (c) Efficacy, (d) Global Centrism, (e) Interconnectedness, and (f) TMAS Score.

A one-way between groups multivariate analysis of variance was performed to investigate differences in teacher candidates' global mindedness and attitudes about teaching culturally and linguistically diverse students between the two groups of teacher candidates who have traveled abroad vs. teacher candidates who have not traveled abroad. Six dependent variables were used: (a) Responsibility, (b) Cultural Pluralism, (c) Efficacy, (d) Global Centrism, (e) Interconnectedness, and (f) TMAS Score. Preliminary assumption testing was conducted to check for normality, linearity, outliers (univariate and multivariate) homogeneity of variance-covariance matrices, and multicollinearity. There were no violations of these assumptions. Due to multiple testing of the dependent variables using six independent variables in six different one-way MANOVA's, the level for significance was adjusted to .0225 . This adjustment allowed for protection against Type I error while keeping the experiment-wise error rate below .10. There was not a statistically significant difference between the two groups of teacher candidates who have traveled abroad vs. teacher candidates who have not traveled abroad on the combined dependent variables. When considered separately, one dependent variable, Cultural Pluralism, indicated significance, $F(1,100)=5.39, p=.022$, partial eta squared $=.051$. A review of the mean scores for the two groups indicated that teacher candidates who have traveled abroad reported higher levels of Cultural Pluralism $(M=32.64, S D=3.64)$ than teacher candidates who have not traveled abroad $(M=30.88, S D=3.95)$.

Reject Null Hypothesis 4e because there is sufficient evidence to indicate that the two groups of teacher candidates who have traveled abroad vs. teacher candidates who 
have not traveled abroad significantly differ in their mean scores on the dependent variable of Cultural Pluralism.

Null Hypothesis 4f: There is not a statistically significant difference in the mean scores between teacher candidates who profess exposure to domestic diversity vs. those who claim to not have exposure to domestic diversity in terms of the six latent variable constructs of (a) Responsibility, (b) Cultural Pluralism, (c) Efficacy, (d) Global Centrism, (e) Interconnectedness, and (f) TMAS Score.

Alternative Hypothesis 4f: There is at least one statistically significant difference in the mean scores between teacher candidates who profess exposure to domestic diversity vs. those who claim to not have exposure to domestic diversity in terms of the six latent variable constructs of (a) Responsibility, (b) Cultural Pluralism, (c) Efficacy, (d) Global Centrism, (e) Interconnectedness, and (f) TMAS Score.

A one-way between groups multivariate analysis of variance was performed to investigate differences in teacher candidates' global mindedness and attitudes about teaching culturally and linguistically diverse students between the two groups of teacher candidates who profess exposure to domestic diversity vs. those who claim to not have exposure to domestic diversity. Six dependent variables were used: (a) Responsibility, (b) Cultural Pluralism, (c) Efficacy, (d) Global Centrism, (e) Interconnectedness, and (f) TMAS Score. Preliminary assumption testing was conducted to check for normality, linearity, outliers (univariate and multivariate) homogeneity of variance-covariance matrices, and multicollinearity. There were no violations of these assumptions. Due to multiple testing of the dependent variables using six independent variables in six different one-way MANOVA's, the level for significance was adjusted to .0225. This adjustment 
allowed for protection against Type I error while keeping the experiment-wise error rate below .10. There was not a statistically significant difference between the two groups of teacher candidates who have traveled abroad vs. teacher candidates who have not traveled abroad on the combined dependent variables. When considered separately, one dependent variable, Efficacy, indicated significance, $F(1,100)=8.40, p=.005$, partial eta squared $=.077$. A review of the mean scores for the two groups indicated that teacher candidates who report some exposure to domestic diversity reported higher levels of Efficacy $(M=19.34, S D=2.49)$ than teacher candidates report no exposure to domestic diversity $(M=17.57, S D=2.90)$.

Reject Null Hypothesis 4f because there is sufficient evidence to indicate that the two groups of teacher candidates who profess exposure to domestic diversity vs. those who claim to not have exposure to domestic diversity significantly differ in their mean scores on the dependent variable of Efficacy.

Null Hypothesis 4g: There is not a statistically significant difference in the mean scores between teacher candidates who speak more than one language vs. those who speak one language in terms of the six latent variable constructs of (a) Responsibility, (b) Cultural Pluralism, (c) Efficacy, (d) Global Centrism, (e) Interconnectedness, and (f) TMAS Score.

Alternative Hypothesis 4g: There is at least one statistically significant difference in the mean scores between teacher candidates who speak more than one language vs. those who speak one language in terms of the six latent variable constructs of (a) Responsibility, (b) Cultural Pluralism, (c) Efficacy, (d) Global Centrism, (e) Interconnectedness, and (f) TMAS Score. 
A one-way between groups multivariate analysis of variance was performed to investigate differences between teacher candidates who speak more than one language vs. those who speak one language in their global mindedness and attitudes about teaching culturally and linguistically diverse students. Six dependent variables were used: (a) Responsibility, (b) Cultural Pluralism, (c) Efficacy, (d) Global Centrism, (e) Interconnectedness, and (f) TMAS Score. Preliminary assumption testing was conducted to check for normality, linearity, outliers (univariate and multivariate) homogeneity of variance-covariance matrices, and multicollinearity. There were no violations of these assumptions. Due to multiple testing of the dependent variables using six independent variables in six different one-way MANOVA's, the level for significance was adjusted to .0225. This adjustment allowed for protection against Type I error while keeping the experiment-wise error rate below .10. There was not a statistically significant difference between teacher candidates who speak more than one language vs. those who speak one language on the combined dependent variables. There were also no statistically significant results when each of the dependent variables was considered separately.

Do not reject Null Hypothesis 4g, because there is insufficient evidence to indicate statistically significances in the mean scores of teacher candidates who speak more than one language vs. those who speak one language in terms of any of the six dependent variable constructs.

\section{Summary}

Chapter 4 began with a description of the demographics of the participants in the study. Following the report of demographics, inferential analysis variable constructs were briefly defined. Information pertaining to required assumptions for the inferential 
analyses was discussed, and any remedies or allowances for possible assumption violations were defined. Reliability information was reported for the seven latent variable constructs used for inferential analysis.

Following the demographic and assumptions section, the research questions were defined in terms of statistical hypotheses.

Hypothesis testing was then performed.

Hypothesis 1 stated that there is a statistically significant difference in mean scores on at least one of the six latent variable constructs between the two groups of (a) teacher candidates who had a bachelor's degree before beginning the education program, vs. (b) teacher candidates who began the education program before obtaining a bachelor's degree. One sample t-tests for performed for Hypothesis 1. Statistical significance was indicated on five of the six variable constructs. Hypothesis 1 was supported.

Hypothesis 2 stated that there is a statistically significant difference in mean scores between the two groups of (a) teacher candidates who had a bachelor's degree before beginning the education program, vs. (b) teacher candidates who began the education program before obtaining a bachelor's degree. Independent samples t-tests were performed for Hypothesis 2. The difference between the mean scores of the groups was statistically significant. Hypothesis 2 was supported.

Hypothesis 3 stated that there is a statistically significant correlation between the summed scores of the two survey instruments: (a) The Global Mindedness Scale (GMS Score), and (b) The Teacher Multicultural Attitude Survey (TMAS).

Pearson's product moment correlation was performed to assess the relationship between the summed scores of the two variables. Hypothesis 3 was supported. 
Hypothesis 4a stated that there is at least one statistically significant correlation between the variable of age and the summed scores on the six latent variable constructs of (a) Responsibility, (b) Cultural Pluralism, (c) Efficacy, (d) Global Centrism, (e) Interconnectedness, and (f) TMAS Score. One correlation, between the two variables of Age and Cultural Pluralism was significant. Hypothesis 4a was supported.

Hypothesis $4 \mathrm{~b}$ stated that there is at least one statistically significant difference in the mean scores of male and female teacher candidates in terms of the six latent variable constructs of (a) Responsibility, (b) Cultural Pluralism, (c) Efficacy, (d) Global Centrism, (e) Interconnectedness, and (f) TMAS Score. Hypothesis 4b was not supported.

Hypothesis 4c stated that there is at least one statistically significant difference in the mean scores of teacher candidates with teaching experience vs. teacher candidates without teaching experience in terms of the six latent variable constructs of (a) Responsibility, (b) Cultural Pluralism, (c) Efficacy, (d) Global Centrism, (e) Interconnectedness, and (f) TMAS Score. One-way MANOVA was performed. the two groups significantly differed in their mean scores on the dependent variable of Interconnectedness. Hypothesis 4c was supported.

Hypothesis $4 \mathrm{~d}$ stated that there is at least one statistically significant difference in the mean scores of teacher candidates with 3 or more courses in global/multicultural issues vs. teacher candidates with less than 3 courses in global/multicultural issues in terms of the six latent variable constructs of (a) Responsibility, (b) Cultural Pluralism, (c) Efficacy, (d) Global Centrism, (e) Interconnectedness, and (f) TMAS Score. One-way MANOVA was performed. the two groups significantly differed in their mean scores on the dependent variable of Cultural Pluralism. Hypothesis 4d was supported. 
Hypothesis 4e stated that there is at least one statistically significant difference in the mean scores between teacher candidates who have traveled abroad and those who have not traveled abroad in terms of the six latent variable constructs of (a) Responsibility, (b) Cultural Pluralism, (c) Efficacy, (d) Global Centrism, (e) Interconnectedness, and (f) TMAS Score. One-way MANOVA was performed. the two groups significantly differed in their mean scores on the dependent variable of Cultural Pluralism. Hypothesis 4e was supported.

Hypothesis $4 \mathrm{f}$ stated that there is at least one statistically significant difference in the mean scores between teacher candidates who profess exposure to domestic diversity vs. those who claim to not have exposure to domestic diversity in terms of the six latent variable constructs of (a) Responsibility, (b) Cultural Pluralism, (c) Efficacy, (d) Global Centrism, (e) Interconnectedness, and (f) TMAS Score. One-way MANOVA was performed. The two groups significantly differed in their mean scores on the dependent variable of Efficacy. Hypothesis $4 \mathrm{f}$ was supported.

Hypothesis $4 \mathrm{~g}$ stated that there is at least one statistically significant difference in the mean scores between teacher candidates who speak more than one language vs. those who speak one language in terms of the six latent variable constructs of (a) Responsibility, (b) Cultural Pluralism, (c) Efficacy, (d) Global Centrism, (e) Interconnectedness, and (f) TMAS Score. Hypothesis 4g was not supported. Table 7 summarizes all inferential analyses as relates to the research hypotheses in this study. 
Table 7

Summary of Inferential Analysis Results for Study vis-à-vis the Research Questions $(N=102)$

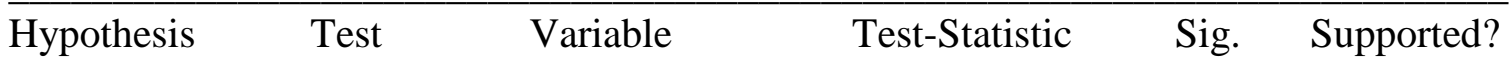

1 How globally minded are teacher candidates? Yes

One-sample t-test

$\begin{array}{lll}\text { GMS score } & \mathrm{t}=15.87 & \mathrm{p}<.0005 \\ \text { Responsibility } & \mathrm{t}=11.91 & \mathrm{p}<.0005 \\ \text { Cultural Pluralism } & \mathrm{t}=19.84 & \mathrm{p}<.0005 \\ \text { Efficacy } & \mathrm{t}=14.85 & \mathrm{p}<.0005 \\ \text { Global Centrism } & \mathrm{t}=4.25 & \mathrm{p}<.0005 \\ \text { Interconnectedness } & \mathrm{t}=10.92 & \mathrm{p}<.0005\end{array}$

2 What is teacher candidates' attitude toward cultural diversity in the classroom? Yes Independent samples t-test

$$
\text { TMAS score } \quad \mathrm{t}=4.27 \quad \mathrm{p}<.0005
$$

3. Is there a relationship between teacher candidates' level of global mindedness and attitude toward diversity in the classroom?

Pearson's product moment correlation

$$
\text { GMS score / TMAS score } \quad \mathrm{r}=.628 \quad \mathrm{p}<01
$$

4. Is there a difference among teacher candidates' global mindedness and attitude towards diversity in the classroom based in the following demographics (Hypotheses $4 \mathrm{~b}-4 \mathrm{~g})$ ?

Hypothesis 4a

Yes

Pearson's product moment correlation

Hypothesis $4 \mathrm{~b}$

$$
\text { Cultural pluralism } \quad \mathrm{r}=.628 \quad \mathrm{p}<.01
$$

MANOVA (Between-Subjects Effects)

No significant results

Hypothesis 4c

Yes

MANOVA (Between-Subjects Effects)

$$
\text { Interconnectedness } \quad \mathrm{F}=5.52 \quad \mathrm{p}=.021
$$


Table 7 Contd.

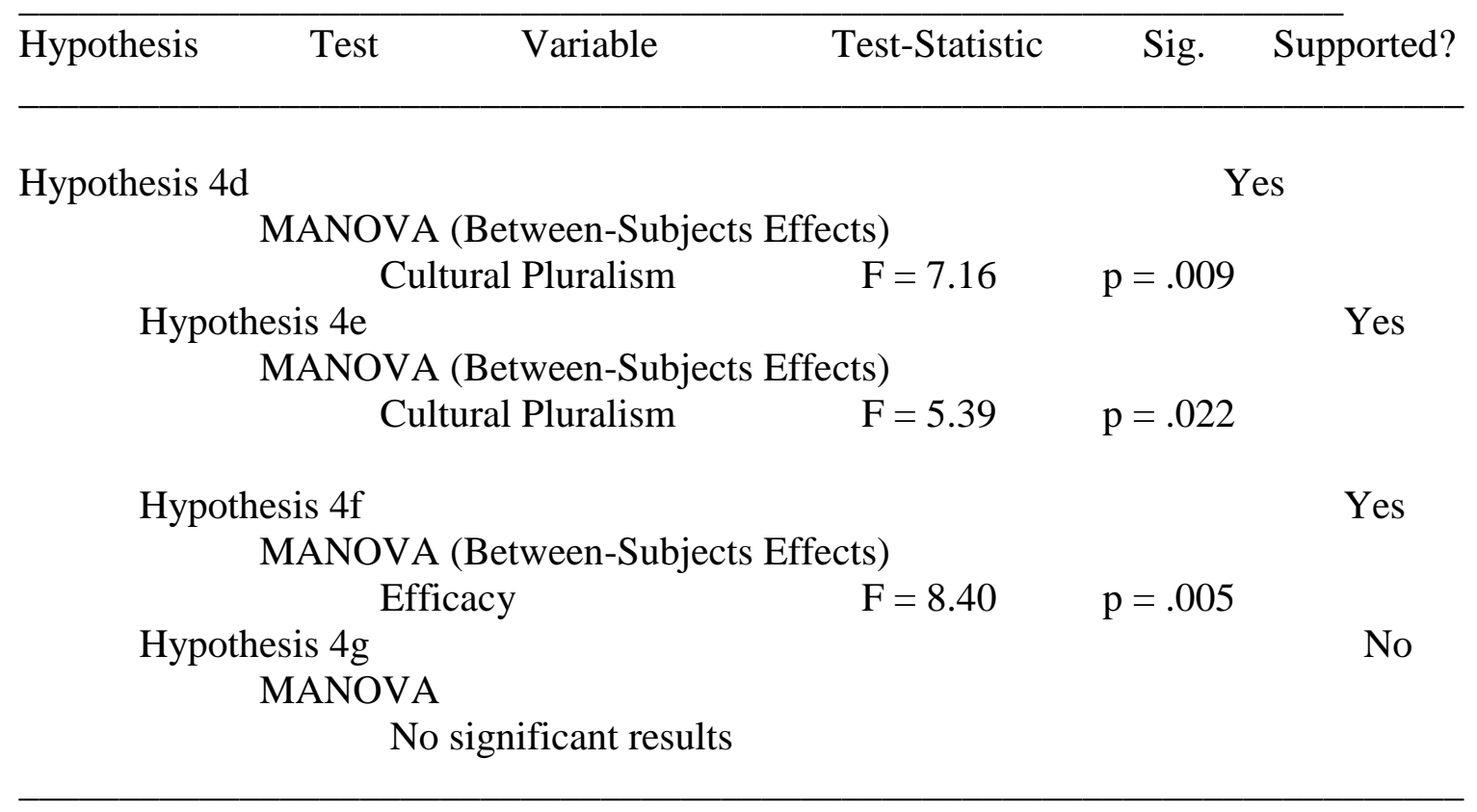

Note. Note. GMS = Global Mindedness Scale; TMAS = Teacher Multicultural Attitude Survey; Sig. = Significance via p-value. 


\section{CHAPTER 5 DISCUSSION}

This final chapter presents a summary of the findings of this study, a discussion of their implications for teacher education, and recommendations for future research. This study examined teacher candidates' global-mindedness and attitudes towards diversity. The sample was drawn from teacher candidates enrolled in fall 2007 education courses at a land grant university. The study explored four research questions:

5. How globally minded are teacher candidates?

6. What is teacher candidates' attitude toward cultural diversity in the classroom?

7. Is there a relationship between teacher candidates' level of global mindedness and attitude toward cultural diversity in the classroom?

8. Is there a difference among teacher candidates' global mindedness and attitudes towards diversity in the classroom based on the following demographics:
a. Age
b. Gender
c. Ethnicity
d. Teaching experience
e. Multicultural/diversity/global courses taken
f. International travel/study abroad
g. Perceived exposure to domestic diversity
h. Religious persuasion/worldview
i. International languages spoken 
Two established survey instruments were used for data collection. The GlobalMindedness Scale (GMS) was used to measure overall global-mindedness and its five dimensions of cultural pluralism, responsibility, efficacy, global-centrism, and interconnectedness. The other instrument, the Teacher Multicultural Attitude Scale (TMAS) was used to measure awareness and attitudes towards cultural diversity. In addition, participants responded to a set of demographic questions, which featured prominently in data analysis.

Using a cross-sectional correlational design, the two teacher candidate groups were conveniently sampled and surveyed. Each completed the Global-Mindedness Scale and the Teacher Multicultural Attitude Scale during the fall 2007 semester. The GMS is a five-point Likert type scale ranging from 1-strongly disagrees to 5-strongly agrees. The TMAS is also a five-point Likert type scale with the same range as the GMS. Comparisons were made between the teacher candidate groups. Overall, we collected One Hundred and Two usable surveys, Fifty-One from each group. From the two scales, seven construct variables were generated for analysis.

Cronbach’s coefficient alpha was used to check the internal consistency reliability of the seven variable constructs with the data obtained in this study. Cronbach’s alpha values for each variable construct are as follows: (a) GMS Score = .895; (b) Responsibility = .717; (c) Cultural Pluralism = .742; (d) Efficacy = .617; (e) Globalcentrism = .602; (f) Interconnectedness $=.676$; and $(\mathrm{g})$ TMAS Score $=.824$.

A Cronbach’s alpha value of .70 or above is considered “acceptable.” All constructs were reliable for the dataset used in this study with the exception of Efficacy, Globalcentrism, and Interconnectedness. However, the Cronbach's alpha scores were not 
far below the threshold level of .70, removing any of the item-responses from an individual construct would not improve the coefficients, and the GMS Score had a "very good” coefficient of .895. Additionally, the scales have been utilized in previous research and possess good test/re-test reliability. Therefore, it was determined that the three lower scoring constructs would be retained for analysis as-is without revisions such as removal of construct item-responses.

For research question number one, the results suggest that the mean values of the participants' scores across all constructs were higher than the actual mean range values of the construct scales, though teacher candidates with a bachelor's degree scored higher than those without degrees. This indicates that this sample of teacher candidates gave responses that are more positive in their answers to the Likert scale items. For the participants in this study, it can be observed that the teacher candidates were positive in their attitudes towards global mindedness and diversity issues. This research supports the assumption that teacher candidates' "awareness” about the recent focus and premium given to issues of globalization and diversity in the school system may have influenced their positive. Additionally, it can be assumed that teacher candidates' positive attitude may have been impacted by the issues of diversity and global mindedness carried by both local and global media outlets. Evans et. al. (1998) assert that students are constantly exposed to situations in college that impact their worldview, growth, and development such as Greek organizations, volunteer community service, and other typical college curricular and co-curricular activities. Finally, the university where the study was conducted is a growing multicultural campus with students from over 50 different countries and from many different states in the United States of America; equally 
relevant is the growing presence minority students other subcultures such as the gay, lesbian and transgender community. Undoubtedly, this level of exposure and cultural contact may have left an indelible global and diversity imprint on the minds of teacher candidates. Statistical significance was indicated on all seven variable constructs.

For research question number two, statistical significance was indicated between the mean scores with teacher candidates who already possessed a bachelor's degree receiving higher scores than those who had not previously obtained a bachelor's degree. The baccalaureate degree experience seemed to have an additional influence on the affective growth of students in their overall global mindedness and attitudes toward diversity in the classroom. This research supports the assumption that previous college experience and exposure to liberal and general education at the undergraduate level contributed to this difference between the two groups of teacher candidates.

For research question number three, Pearson's product moment correlation was performed to assess the relationship between the summed scores of the two variables (a) GMS Score, and (b) TMAS. The correlation between the two variables was strong, positive, and significant, $\mathrm{r}(100)=.628, \mathrm{p}<.01$. The positive correlation suggests that when scores on one of the variables increases or decreases, the values on the other variable move in a like manner. Thus, this research supports the assumption that students exposed to either domestic or global diversity tend to be more positive in their orientation and attitude when confronted with difference. They are cognitively more flexible and have the capacity to tolerate ambiguity with minimal cognitive dissonance.

For question number four, the findings indicated that gender and ability to speak a second or foreign language neither influenced the development of global-mindedness nor 
engendered a positive attitude towards diversity in the classroom in this study. However, age, teaching experience, global/diversity course taken, travel/study abroad, and perceived exposure to domestic diversity showed positive interactions: cultural pluralism registered three positive interactions while interconnectedness and efficacy registered one positive interaction each. Note that though ability to speak a second or foreign language did not have a positive interaction with any of the latent constructs in this study, other studies have reported a strong and positive relationship (Murphy \& Horton, 2003).

As indicated in the methods section, ethnicity and religious persuasion/worldview were discarded in the analysis of research question number four because of the homogeneity of the sample. It could however be assumed that had the sample been heterogeneous, these discarded variable would have been relevant to the study.

\section{Recommendations}

This section is divided into two. Part 1 spells out recommendations for teacher education. Part 2 focuses on suggestions for further research to enhance understanding of the full contours and ramifications of global mindedness and attitudes towards diversity in the classroom.

Implications for teacher education

Since cultural contacts during one's education influences one's attitudes towards diversity, it is strongly recommended that teacher education programs must strive to recruit more minority students domestically as well as reinforce their recruitment of international students. Additionally, it is prudent to expose teacher candidates earlier on in their program to the cultures in which they will be working by making sure their 
teaching practicum is geographically widespread across the United States and across the globe. These interventions will go a long way to enrich teacher candidates' college experience as well as their future careers. Indubitably, teacher candidates should not become culturally challenged practitioners in their classrooms. They must be prepared to play a meaningful role as people and professionals who have the cognitive and behavioral flexibility to engage their culturally diverse students. It is important to note that though the teacher candidates surveyed displayed moderate to high positive attitudes towards global and diversity issues, attitude alone is not enough. The crucial question is to what extent does attitude influence behavior. This poignant question lays bare the need to put teacher candidates in situations where their behavior can be observed to see if they reflect their self-report attitudes.

Evidently, students who had taken globalcentric and diversity oriented courses reported a more positive affect towards issues of diversity and the global community. Against this backdrop, it is suggested that teacher education programs must be recast both philosophically and programmatically as institutions where cultural and global literacy are strategic cogs central to their mission---not to be treated as afterthoughts. Specifically, teacher candidates should be exposed to cultural theories, take classes that focus on diversity and global issues, and conduct action research in settings with diversity in its various ramifications. This rethinking calls for a systematic and sustainable infusion of cultural and global relevance into their curriculum and praxis. The first step in this direction is for teacher educators to do a thorough and an objective assessment of their curriculum to determine the gaps in their global and diversity content and institutional initiatives. Unquestionably, teacher educators and administrators must mirror this 
renaissance if they expect their teacher candidates to be equipped intellectually, emotionally, and behaviorally for the challenges that await them in the classrooms of the $21^{\text {st }}$ century.

Findings from this study indicated that students who were exposed to prior general or liberal education were positively more attuned into the issues of global mindedness and diversity than students without that exposure were. It is therefore recommended that teacher education programs that take students without a solid liberal or general education foundation must incorporate this vital piece of educational experience into their teacher education programs. Incontestably, great teachers are great thinkers; great thinking comes from a well-rounded education. Teacher education programs must take this clarion call seriously else, they shortchange the educational experience of their teacher candidates who will go into the classrooms of the world with little or no cultural literacy. As the adage goes, "we cannot teach what we do not know."

Suggestions for further studies

Though the findings of this study shed light on teacher global mindedness and attitudes towards diversity in the classroom, more research needs to be done to understand the full range and impact of teacher perceptions and attitudes towards global and diversity issues in the classroom.

The first avenue that needs to be conducted in future teacher global mindedness and attitudes towards diversity in the classroom research is to get a wider participation base. While the information about the measures is greatly helped in this project, the overall implications that could exist between some of the variables can only be truly explored if a 
more generalized populace were to participate in this specific study.

A second avenue for future research in teacher global mindedness and attitudes towards diversity in the classroom is conduct a comparative study between practicing teachers and teacher candidates to determine whether there are significant differences between their perceptions and attitudes. Understanding how these two groups differ or do not differ would be very helpful in appreciating the role of experience and experiential learning in the formation and development of perceptions and attitudes about global and diversity issues in the classroom.

A third avenue for research is in designing a pretest and posttest study to measure the difference, if any, between teacher candidates global mindedness and attitudes towards diversity. This study could be done various ways. One possibility is to measure teacher candidates' perceptions and attitudes before and after a teaching abroad experience or before and after a semester-long immersion in global /diversity curricular and extracurricular activities on campus. Another possibility is to conduct a longitudinal study where teacher candidates' perceptions and attitudes about global/diversity issues would be measured while they are in school and five years into their real teaching experience. These research interventions would help shed light on the place of experience and cultural contact on teacher attitudes and perceptions about global/diversity issues.

A fourth avenue for teacher global mindedness and attitudes towards diversity in the classroom is to examine the same perceptions and attitudes from the faculty and administrators of teacher education programs. The information that would be gleaned would be a strong testament and commentary on the premium placed on global/diversity 
issues in teacher education programs.

A fifth avenue for research is to do a content evaluative research on the curriculum of teacher education programs to determine the focus, breadth and depth of their global/diversity content. This kind of study can help teacher educators to rethink, recalibrate, or reinforce their global/diversity content and initiatives. 


\section{References}

Apple, M. W., Kenway, J., \& Singh, M. (Eds.) (2005). Globalizing education: Policies, pedagogies, and politics. New York: Peter Lang.

Artiles, A. J. (2003). Special education's changing identity: Paradoxes and dilemmas in views of culture and space. Harvard Educational Review, 73 (2), 164-202, 247.

Asimeng-Boahene, L., \& Klein, A. M. (2004). Is the diversity issue a non-issue in mainstream academia? Multicultural Education, 12(1), 47-52.

Baker, F. J. (1999). Multicultural versus global education: Why not two sides of the same coin? Teacher Education. The Journal of Interdisciplinary Studies, 12, Fall 1999, 97-101.

Banks, J. A. (1997). Teaching strategies for ethnic studies. (6th ed). Boston: Allyn and Bacon.

Banks J. (1999). Series Foreword. In G. R. Howard, We can’t teach what we don’t know (p. ix-xi). New York: Teachers College Press.

Banks, J. (2001 a). Multicultural education: Characteristics and goals. In J. A. Banks, \& C. A. M. Banks (Eds.), Multicultural education: Issues \& perspectives (pp.3-30). New York: Wiley.

Banks, J. (200l b). Approaches to multicultural curriculum reform. In J. A. Banks, \& C. A. M. Banks (Eds.), Multicultural education: issues \& perspectives (pp. 225 -246) New York: Wiley.

Banks, J. A. \& Banks, C. A. M. (2001). Preface. In J. A. Banks, \& C. A. M. Banks (Eds.), Multicultural education: Issues \& perspectives (pp. v-vii). New York: Wiley. 
Banks, J. (2004). Democratic citizenship: Education in multicultural societies. In J. Banks (Ed.), Diversity and citizenship education: Global perspectives (pp. 3-15). Princeton: Princeton University Press.

Beamer, L. \& Varner, I. (2001). Intercultural communication in the global workplace (2nd ed.) Massachusetts: McGraw-Hill/Irwin.

Bennett, L. (1990). Multicultural Education Issues. New York: Prentice Hall.

Bennett, C. (1995). Comprehensive multicultural education: Theory and practice. Needham Heights, MA: Allyn and Bacon.

Betsinger, A. M., Garcia, S. B., \& Guerra, P., L. (2000). Research report for the organizing for diversity project. Austin, TX: Southwest Educational Development Lab. (ERIC Document Reproduction Service No. ED 449 260)

Bhargava, A., Hawley, L. D., Scott, C.L., Stein, M., \& Phelps, A. (2004). An investigation of students' perceptions of multicultural education experiences in a school of education. Multicultural Education, 11(4), 18-22.

Brislin, R. (2000). Understanding culture's influence on behavior. Fort Worth, TX:

Harcourt College.

Byram, M. (1997). Teaching and assessing intercultural communicative competence. Clevedon, UK: Multilingual Matters.

Capella-Santana, N. (2003) 'Voices of teacher candidates: positive changes in multicultural attitudes and knowledge’. The Journal of Education Research 96(3): 182-9. 
Chamberlain, S. P. (2005). Recognizing and responding to cultural differences in the education of culturally and linguistically diverse learners. Intervention in School and Clinic, 40(4), 195-211.

Chamberlain, S. P., Guerra, P.L., \& Garcia S. B. (1999). Intercultural communication in the classroom. Austin, TX: Southwest Educational Development Lab. (ERIC Document Reproduction Service NO. ED 432 573)

Cochran-Smith, M., Davis, D. \& Fries, K. (2004) 'Multicultural teacher education’, in J.A. Banks and C.A. Banks (eds) Handbook of Research on Multicultural Education. 2nd ed, pp. 931-75. San Francisco, CA: Jossey-Bass, 931-975.

Colombo, M. (2004). Literacy for all students: Professional development for cultural continuity. New England Reading Association Journal, 40(2), 50-54.

Cushner, K, Mahon, J. (2002). Overseas student teaching: Affecting personal, professional, and global competencies in an age of globalization. Journal of Studies in International Education, 6(1) 44-58

Danesi, M., \& Perron, P. (1999). Analyzing cultures: An introduction \& handbook. Bloomington, IN: Indiana University Press.

Davies, L. (2006). Global citizenship: Abstraction or framework for action? Educational Review, 58(1), 5-25.

De Jong, E. J., \& Harper, C. A. (2005). Preparing mainstream teachers for Englishlanguage learners: Is being a good teacher good enough? Teacher Education Quarterly, 32(2), 101-124 
Delpit, L. (1995). Other people's children: Cultural conflict in the classroom. New York: The New York Press.

Dogancay-Aktuna, S. (2005) Intercultural communication in English language teacher education. ELT Journal, 59(2), 99-107.

Easter, L.M., Shultz, E.L. , Neyhart, T.K. \& Reck, U.M. (1999) 'Weighty perceptions: A study of the attitudes and beliefs of preservice teacher education students regarding diversity and urban education’. The Urban Review 31(2): 20520.

Evans, M. (2006). Educating for citizenship: What teachers say and what teachers do. Canadian Journal of Education, 35(2), 410-436.

Evans, M., \& Reynolds, C. (Eds). (2004). Educating for global citizenship in a changing world: A teacher's resource handbook. Toronto: OISE/UT-CIDA.

Franzway, S. (2005). Making progressive educational politics in the current global crisis. In M. W. Apple, J. Kenway, \& M. Singh (Eds.), Globalizing education: Policies, pedagogies, and politics. New York: Peter Lang.

Friedman, T. L. (2005). The world is flat: A brief history of the twenty-first century. New York: Farrar, Strauss, and Giroux.

Galambos, C. M. (2003). Moving cultural diversity toward cultural competence in health care. Health \& Social Work, 28 (1), 3-7.

Garcia, E. (1999). Student cultural diversity: understanding and meeting the challenge (2nd Ed). New York: Houghton Mifflin. 
Garcia, S. B., \& Guerra, P. L. (2004). Deconstructing deficit thinking: Working with educators to create more equitable learning environments. Education and Urban Society, 36(2), 150-168.

Gay, G. (2002). Culturally responsive teaching: Theory, research \& practice. New York: Teachers College Press.

Gay, G. (2001). Educational equality for students of color. In J.A. Banks, \& C. A. M. Banks (Eds.), Multicultural education: Issues \& Perspectives (pp. 197-224). New York: Wiley.

Gay, G., \& Howard, T. C. (2000). Multicultural education for the $21^{\text {st }}$ century. The Teacher Educator, 36(1), 1-16.

Gay, G. \& Kirkland, K. (2003). Developing cultural critical consciousness and selfreflection in preservice teacher education. Theory into Practice, 42(3), 265-276.

Gibson, M. A. (1998). Promoting academic success among immigrant students: Is acculturation the issue? Education Policy, 12, 615-633.

Grogan, S., \& Eshelman, B. (1998). Staffing strategies for a more diverse workforce: Case examples in Cornell cooperative extension. Journal of Extension, 36(1). Retrieved July 18, 2005 from: http://www.joe.org/joe/1998feburary/ a1.html

Grant C.A., \& Sleeter, C.E. (2001). Race, class, gender, and disability in the classroom. In J. A. Banks, \& C. A. M. Banks (Eds.), Multicultural education: Issues \& perspectives (pp. 59-81). New York: Wiley. 
Greenleaf, C., Hull, G. A., \& Reilly, B. (1994)Learning from our diverse students:

Helping teachers rethink problematic teaching and learning situation. Teaching \& Teacher Education, 10(5), 521-541.

Gudykunst, W.B. Cultural variability in communication. Communication Research, August 1997, v24, Is 4, p. 327, 22p.

Gudykunst, W. \& Mody, B. (2001). Handbook of International and Intercultural Communication California: Sage

Gudykunst, W., Stewart, L.P., \& Ting-Toomey, S. (Ed.) (1985).

Communalization, culture, and organizational processes. (International and Intercultural Communication Annual, Vol. IX, 1985). California: Newbury Park.

Gudykunst, W.B. \& Ting-Toomey, S. (1988). Culture and interpersonal communication. California: Sage.

Gudykunst, W. (2004). Bridging differences: Effective intergroup communication. Thousand Oaks, CA: Sage.

Gudykunst, W. B., \& Kim, Y. Y. (1992). Communicating with strangers: An approach to intercultural communication. New York: McGraw-Hill.

Hall, E. T. (1976) Beyond culture. New York: Anchor.

Hayakawa, S. I. (1963). Symbol, status, and personality. New York: Harvest Book: Harcourt, Brace \& World.

Hayden, M.C., Rancic, B.A. \& Thompson, J. J. (2000) ‘Being international: Student and teacher perceptions from international schools’. Oxford Review of Education 26(1): 107-24. 
Helms, S. M. (2004). The examination of cultural sensitivity and exhibition of cultural competence for faculty at liberal arts institutions within higher education. Dissertation Abstracts International, 64(10), 3609A. (UMI No. 3107769)

Hett, E. J. (1993). The development of an instrument to measure global mindedness. Unpublished Doctoral Dissertation, University of San Diego.

Hofstede, G. (1980). Culture’s consequences. California: Sage.

Hofstede, G., \& Hofstede, G. J. (2005). Cultures and organization: Software of the mind. New York: McGraw-Hill.

Hollins, E. (1996). Culture in school learning. Mahwah, NJ: Erlbaum

Howard, G. R. (1999). We can't teach what we don't know. New York: Teachers College Press.

Huck, S.W. (2008). Reading Statistics and Research (5 ${ }^{\text {th }}$ Ed). New York: Pearson Hyon, S., \& Sulzby, E. (1992). Black kindergartners’ spoken narratives: Style, structure, and task. (ERIC document reproduction service No. ED 352 148).

Irvine, J. J. (2001). The critical element of culturally responsive pedagogy: A synthesis of the research. In J. J. Irinve, B. J. Armento, V. E. Causey, J. C. Jones, R. S. Frasher, \& M. H. Weinburgh (Eds.), Culturally responsive teaching: Lesson planning for elementary and middle grades (pp3-17). Boston: McGraw-Hill. Jandt, F. E. (2004). An introduction to intercultural communication: Identity in a global community. Thousand Oaks, CA: Sage.

Kim, Y. Y. (1986). Interethnic communication: current research. California: Sage. Kirkwood, T.F. (2001). Our global age requires global education: Clarifying definitional ambiguities. The Social Studies. 92(1), 10-15 
Ladson-Billings, G. (1995). Multicultural teacher education: Research, practice, and policy. In J. A. Banks, \& C. A. M. Banks (Eds.), Handbook of research on multicultural education (pp. 747-759). New York: Macmillan.

Macedo, Stephen (2000). Diversity and distrust civic education in a multicultural society. New Jersey: Harvard University.

Marris, P. (1996). The politics of uncertainty. New York: Routledge.

Martin, J.N. \& Nakayama, T.K. (2007). Intercultural communication in contexts. New York: Mcgraw-Hill

Menyuk, P. (1999). Reading and linguistic development. Cambridge, MA: Brookline Books.

Merryfield, M. (1996). Making connections between multicultural and global education: Teacher educators and teacher education programs. Washington DC: American Association of Colleges for Teacher Education.

Mikkelsen, N. (1990). Toward greater equity in literacy education: Storymaking and nonmainstream students. Language Arts, 67, 556-566

Milner, H. R., Flowers, L. A., Moore, E., Moore, J. L., \& Flowers, T. A. (2003). Preservice teachers' awareness of multiculturalism and diversity. The High School Journal, 87(1), 63-70.

Moll, L. C., \& Arnot-Hopffer, E. (2005). Sociocultural competence in teaching education. Journal of Teacher Education, 56(3), 242-247. 
Moll, L. C., Atnanti, C., \& Neff, D. (1992). Funds of knowledge for teaching: Using a qualitative approach to connect homes and classrooms. Theory into Practice, 31, $132-141$.

Mujawamariya, D., \& Mahrouse, G. (2004). Multicultural education in Canadian perspective programs: Teacher candidates' perspectives. The Alberta Journal of Educational Research, 50(4), 336-353.

Nieto, S. (2000). Affirming diversity: The sociopolitical context of multicultural education. New York: Longman.

Nisha, D. \& Nirajan, K. (2003). First-Year Medical Students' Attitudes toward Diversity and its Teaching: An Investigation at One U.S. Medical School. Journal of the Association of American College, 78(11), 1191-1200.

Noddings, N. (2005). Educating citizens for global awareness. New York: Teachers College Press.

Odell, K. S., Williams, M.E., Lawrence, L. D., Gartin, S.A., \& Smith, D. K. (2002). Evaluation of the international 4-H youth exchange (IFYE) Program. Journal of International Agricultural and Extension Education, 9 (1), 57-64.

Pike, G. R. (2002). The differential effects of on- and off-campus living arrangements on students' openness to diversity. NASPA Journal, 39 (4), 283290. Stanley, L. S. (1996). The development and validation of an instrument to assess attitudes toward cultural diversity and pluralism among pre-service physical educators. Educational and Psychological Measurement, 56 (5), 864870. 
Ponterotto, J. G., Baluch, S., Greig, T., \& Rivera, L. (1998). Development and initial score validation of the teacher multicultural attitude survey. Educational and psychological measurement, 58(6), 1002-1016.

Quezada, R. L. (2004). Beyond educational tourism: Lessons learned while student teaching abroad. International Education Journal, 5(4), 458-465.

Razzano, E. (1996) 'The overseas route to multicultural and international education'. The Clearing House 69(5): 268-70.

Rothstein-Fisch, C., Greenfield, P. M., \& Trumbull, E. (1999). Bridging cultures with classroom strategies. Educational Leadership, 56(7). 64-66.

Samovar, L.A. \& Porter, R.E. (2001). Communication between cultures (4th Ed). Massachusetts: Wadsworth/Thomson.

Samovar, L.A., Porter, R.E. \& McDaniel, E.R. (2007). Communication between cultures (4th Ed). Massachusetts: Wadsworth/Thomson.

Sampson, D. L. \& Smith, H. P. (1957). World-Mindedness Scale.

Sleeter, C. E., \& Grant, C. A. (2003) Making choices for multicultural education: Five approaches to race, class, and gender. New York: Wiley.

Thompson, G. (2002) 'Teachers studying abroad: an analysis of changes in linguistic and cultural knowledge and attitudes toward the Spanish culture and the effects of ethnographic interviews'. Paper presented at the TexFlec Conference, Austin, TX, March.

Torres, C. A. (2002). Globalization, education, and citizenship: Solidarity versus market? American Educational Research Journal, 39 (2), 363-373. 
Triandis, H.C. (1984). A theoretical framework for the more efficient construction of cultural assimilators. International Journal of Intercultural Relations, 8, 301330.

Trumbull, E., Greenfield, P. M., \& Quiroz, B. (2003). Cultural values in learning and education. In B. William (Ed.), Closing the achievement gap: A vision for changing beliefs and practices (pp. 67-98), Alexandria, VA: Association for Supervision and Curriculum Development.

Van Hook, C.W. (2000) 'Preparing teachers for the diverse classroom:

a developmental model of intercultural sensitivity’. Issues of Early Childhood Education: Curriculum, Teacher Education \& Dissemination of Information (presented at the Proceedings of the Lilian Katz Symposium, November).

Welch, A. (2002). Going global? Internationalizing Australian universities in a at time of global crisis. Comparative Education Review, 46 (4), 433-471.

White-Clark, R. (2005). Training teachers to succeed in a multicultural climate. Principal, 84(4), 40-44.

Zhai, L., \& Scheer, S. D. (2002). The influence of international experience on agriculture student personal development. Journal of International Agricultural and Extension Education, 9 (3), 23-29. 
Table 1

Frequency Statistics for Demographic Study Variables (N=102)

\begin{tabular}{|c|c|c|}
\hline Variable & Frequency & Percentage \\
\hline \multicolumn{3}{|l|}{ Gender } \\
\hline Male & 29 & 28.4 \\
\hline Female & 73 & 71.6 \\
\hline \multicolumn{3}{|l|}{ Age (in years) } \\
\hline 21 & 1 & 1.0 \\
\hline 22 & 35 & 34.3 \\
\hline 23 & 36 & 35.3 \\
\hline 24 & 11 & 10.8 \\
\hline 25 & 5 & 4.9 \\
\hline 26 & 2 & 2.0 \\
\hline 27 & 3 & 2.9 \\
\hline 28 & 2 & 2.0 \\
\hline 29 & 3 & 2.9 \\
\hline 30 & 1 & 1.0 \\
\hline 32 & 1 & 1.0 \\
\hline 35 & 1 & 1.0 \\
\hline 39 & 1 & 1.0 \\
\hline
\end{tabular}


Table 1 (cont'd)

\begin{tabular}{llc} 
Variable & Frequency & Percentage \\
\hline
\end{tabular}

Ethnicity

African-American

Caucasian

Asian

Program type

Post-baccalaureate

5-year

Teaching experience

Yes

No

International exposure

Yes

No

Worldview

Christian

Jewish

Spiritual

Other
1

1.0

100

98.0

1

1.0

51

50.0

51

50.0

57

45

44.1

45

44.1

57

79

77.5

1

1.0

4

3.9

18

17.6 
Table 1 (cont'd)

Variable

Frequency

Percentage

Relevant courses

3 or more

50

49.0

Less than 2

52

51.0

Languages spoken

English only

58

56.9

English and another

44

43.1

Perceived exposure to domestic diversity

Some experience

79

77.5

No experience

23

22.5 
Table 2

Latent Variable constructs for Study, and Associated Response Item Numbers, According to Survey Instrument $(N=102)$

Variable

GMS

Global mindedness

Responsibility

Cultural pluralism

Efficacy

Globalcentrism

Interconnectedness

TMAS

Multicultural attitude
Associated response item numbers

Response items 21 - 50 inclusive (reverse score items 24, 25, 29, 30, $36,41,45,47,49$ )

22, 27, 32, 38, 43, 46, 50

$21,23,28,33,34,39,44,47$

24, 29, 35, 40, 48

$25,30,36,41,49$

26, 31, 37, 42, 45
Response items 1 - 20 inclusive (reverse score items 3, 6, 12, 15, 16, 19, 20)

Note. GMS = Global Mindedness Scale; TMAS = Teacher Multicultural Attitude Survey. 
Table 3

Descriptive Statistics for Summed Latent Variable Constructs as Relates to Inferential Hypotheses $(N=102)$

\begin{tabular}{lccccc}
\hline Variable & $M$ & SE $M$ & SD & $\begin{array}{c}\text { Possible } \\
\text { Range }\end{array}$ & $\begin{array}{c}\text { Sample } \\
\text { Range }\end{array}$ \\
\hline GMS (90) & 100.63 & 1.30 & 13.13 & $30-150$ & $68-147$ \\
Responsibility (21) & 25.48 & 0.38 & 3.80 & $7-35$ & $15-35$ \\
Cultural pluralism (24) & 31.66 & 0.39 & 3.90 & $8-40$ & $20-39$ \\
Efficacy (15) & 18.94 & 0.27 & 2.68 & $5-25$ & $11-25$ \\
Global centrism (15) & 16.23 & 0.29 & 2.91 & $5-25$ & $10-25$ \\
Interconnectedness (15) & 18.32 & 0.31 & 3.07 & $5-25$ & $8-25$ \\
TMAS (60) & 77.69 & 0.80 & 8.08 & $20-100$ & $58-96$ \\
\hline
\end{tabular}

Note. GMS = Global Mindedness Scale; TMAS = Teacher Multicultural Attitude Survey. Values in parentheses indicate mean score values for the given construct scale. 
Table 4

Summary of Results for Independent Samples t-tests as Relates to Hypothesis 1, Comparison of Teacher Candidates who Possessed a Bachelor's Degree $(n=51)$ vs.

Teacher Candidates Who Had Not Previously Obtained a Bachelor's Degree $(n=51)$, $(N=102)$

\begin{tabular}{lccccc}
\hline $\begin{array}{l}\text { Variable } \\
\text { Supported? }\end{array}$ & Mean Score & Mean Score & Diff & $t$ & Sig. \\
& B.A./B.S. & No B.A./B.S & & & \\
\hline $\begin{array}{l}\text { GMS Score } \\
\text { Yes }\end{array}$ & 116.08 & 105.18 & 10.90 & 4.59 & $\mathrm{p}<.0005$ \\
$\begin{array}{l}\text { Responsibility } \\
\text { Yes }\end{array}$ & 26.69 & 24.27 & 2.42 & 3.37 & $\mathrm{p}<.0005$ \\
$\begin{array}{l}\text { Cultural pluralism } \\
\text { Yes }\end{array}$ & 33.27 & 30.04 & 3.23 & 4.59 & $\mathrm{p}<.0005$ \\
$\begin{array}{l}\text { Efficacy } \\
\text { Yes } \\
\begin{array}{l}\text { Global centrism } \\
\text { No }\end{array}\end{array}$ & 19.94 & 17.94 & 2.00 & 4.04 & $\mathrm{p}<.0005$ \\
$\begin{array}{l}\text { Interconnectedness } \\
\text { Yes }\end{array}$ & 19.41 & 15.69 & 1.07 & 1.46 & $\mathrm{p}=.061$ \\
& & 17.24 & 2.17 & 3.81 & $\mathrm{p}<.0005$ \\
\hline
\end{tabular}

Note. GMS = Global Mindedness Scale; TMAS = Teacher Multicultural Attitude Survey; Diff = Difference in Mean Scores; Sig. = Significance via p-value. 
Table 5

Summary of Results for Independent Samples t-tests as Relates to Hypothesis 2,

Comparison of Teacher Candidates who Possessed a Bachelor's Degree $(n=51)$ vs.

Teacher Candidates Who Had Not Previously Obtained a Bachelor's Degree $(n=51)$,

$(N=102)$

Variable

Mean Score Mean Score

Diff

$t$

Sig.

Supported?

B.A./B.S. No B.A./B.S

TMAS score

80.84

74.53

6.31

4.27

$\mathrm{p}<.0005$

Yes

Note. TMAS = Teacher Multicultural Attitude Survey; Diff = Difference in Mean Scores; Sig. = Significance via $\mathrm{p}$-value. 
Table 6

Summary of Significant Results for Pearson's Product Moment Correlation (Hypothesis 4a) and One-Way MANOVA Analyses (Hypotheses 4b-4g) as Relates to Hypothesis 4, Comparison of Sample Independent Demographic Variables with Study Latent Variable Constructs $(N=102)$

\begin{tabular}{llllll}
\hline Hypothesis/Variable & Test & $d f$ & $F$ & part $\eta^{2}$ & $p$ \\
Supported?
\end{tabular}

Hypothesis 4a Cultural pluralism Yes

Hypothesis $4 \mathrm{~b}$
Pearson's product moment correlation

$$
\mathrm{r}(100)=.628, \mathrm{p}<.01
$$

MANOVA (Between-Subjects Effects)

No significant results

No

Hypothesis 4c Interconnectedness Yes

Hypothesis 4d Cultural Pluralism Yes

Hypothesis 4e

Cultural Pluralism Yes

Hypothesis $4 \mathrm{f}$ Efficacy Yes
MANOVA (Between-Subjects Effects)

$$
\begin{array}{llll}
1 & 5.52 & .052 & .021
\end{array}
$$

MANOVA (Between-Subjects Effects)

$$
\begin{array}{llll}
1 & 7.16 & .067 & .009
\end{array}
$$

MANOVA (Between-Subjects Effects)

$$
\begin{array}{llll}
1 & 5.39 & .051 & .022
\end{array}
$$

MANOVA (Between-Subjects Effects)

$$
\begin{array}{lll}
1 & 8.40 \quad .077
\end{array}
$$
.005

Hypothesis 4g

MANOVA

No significant results

No 
Table 7 summarizes all inferential analyses as relates to the research hypotheses in this study.

Table 7

Summary of Inferential Analysis Results for Study vis-à-vis the Research Questions $(N=102)$

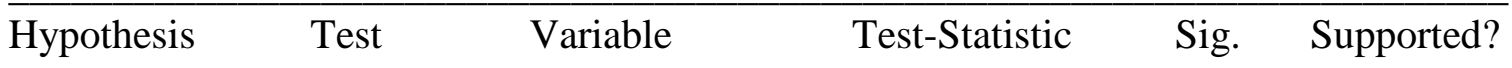

1 How globally minded are teacher candidates? Yes One-sample t-test

$\begin{array}{lll}\text { GMS score } & \mathrm{t}=15.87 & \mathrm{p}<.0005 \\ \text { Responsibility } & \mathrm{t}=11.91 & \mathrm{p}<.0005 \\ \text { Cultural Pluralism } & \mathrm{t}=19.84 & \mathrm{p}<.0005 \\ \text { Efficacy } & \mathrm{t}=14.85 & \mathrm{p}<.0005 \\ \text { Global Centrism } & \mathrm{t}=4.25 & \mathrm{p}<.0005 \\ \text { Interconnectedness } & \mathrm{t}=10.92 & \mathrm{p}<.0005\end{array}$

2 What is teacher candidates' attitude toward cultural diversity in the classroom? Yes Independent samples t-test

$$
\text { TMAS score } \quad \mathrm{t}=4.27 \quad \mathrm{p}<.0005
$$

3. Is there a relationship between teacher candidates' level of global mindedness and attitude toward diversity in the classroom?

Pearson's product moment correlation

$$
\text { GMS score / TMAS score } \quad r=.628 \quad \mathrm{p}<01
$$

4. Is there a difference among teacher candidates' global mindedness and attitude towards diversity in the classroom based in the following demographics (Hypotheses $4 \mathrm{~b}-4 \mathrm{~g})$ ?

Hypothesis 4a Yes

Pearson's product moment correlation

Hypothesis $4 \mathrm{~b}$

$$
\text { Cultural pluralism } \quad \mathrm{r}=.628 \quad \mathrm{p}<.01
$$

MANOVA (Between-Subjects Effects)

No significant results 
Table 7 Contd.

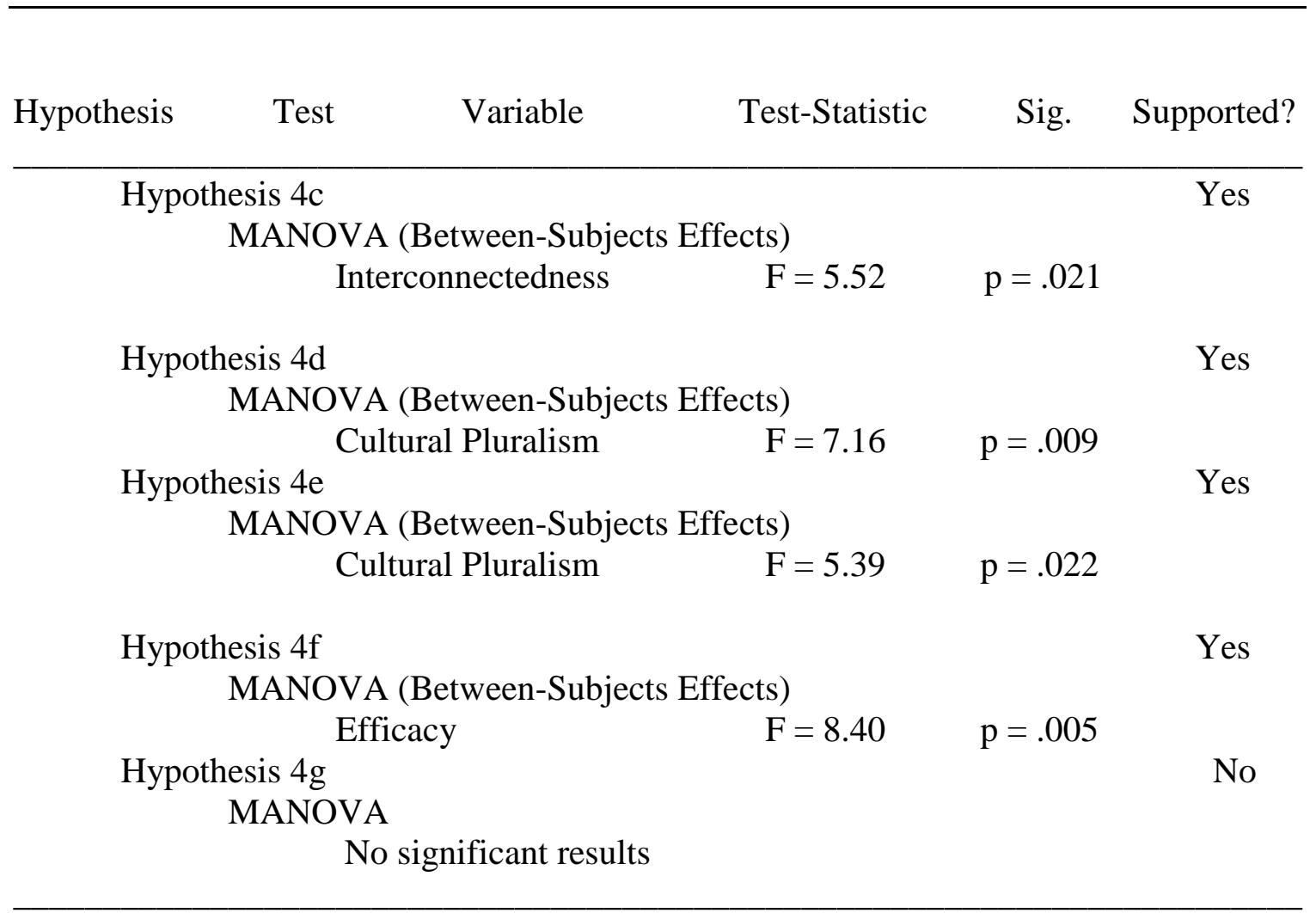

Note. Note. GMS = Global Mindedness Scale; TMAS = Teacher Multicultural Attitude Survey; Sig. = Significance via p-value. 
APPENDIX A

INFORMED CONSENT FORM 


\section{INFORMED CONSENT FORM}

I freely and voluntarily and without element of force or coercion, consent to be a participant in the research project entitled "Global Mindedness and Disposition Towards Cultural Diversity n the Classroom.”

This research is being conducted by Ras Tsidi Acolatse, who is a doctoral candidate at West Virginia University, College of Human Resources and Education/Department of Communication Studies. I understand the purpose of his research project is to understand better teacher candidates' global mindedness and attitudes towards cultural diversity in the classroom. . I understand that if I participate in the project I will be asked questions about my beliefs and attitudes about multicultural issues.

I understand I will be asked to fill out paper and pencil questionnaires. The total time commitment would be about 30 minutes.

I understand my participation is voluntary and I may stop participation at anytime. All my answers to the questions will be kept confidential and identified by a subject code number. My name will not appear on any of the results.

I understand there are benefits for participating in this research project. I will be providing education professionals with valuable insight into how to treat preservice teachers' beliefs and attitudes in teacher education programs.

I understand that this consent may be withdrawn at any time without prejudice, penalty. I have been given the right to ask and have answered any inquiry concerning the study. Questions, if any, have been answered to my satisfaction.

I understand that I may contact Mr. Ras Tsidi Acolatse, (703) 336-9631 or rastaco@hotmail.com, for answers to questions about this research or my rights. Group results will be sent to me upon my request.

I have read and understand this consent form. 
APPENDIX B

Combined Research Instruments 
Dear Study Participants,

I, Ras Tsidi Acolatse, am a doctoral candidate writing my dissertation entitled "Global Mindedness and Disposition Towards Cultural Diversity in the Classroom.” I appreciate your participation in this study.

Please take about 30 minutes to complete the attached Teacher Perceptions and Attitudes Survey. The instrument is divided into three parts. Parts1 and 2 have statements to which you have to indicate your agreement or disagreement by checking the number that best expresses what you think about the statement. Your replies to these statements can range from 1 to 5 .

$1=$ Strongly Disagree

2= Disagree

$3=$ Uncertain

4= Agree

5= Strongly Agree

Part 3 has a set of demographic questions. Just check the box that best represents your situation.

The purpose of this study is to understand better teacher candidates' intercultural awareness and attitude towards cultural diversity in the classroom. Your name will not appear on any of the instruments and $100 \%$ confidentiality is guaranteed.

Please DO NOT write your name on any of the data collection instrument. Your candid responses to the questions on the data collection instrument will be greatly appreciated. Please answer each statement even if you are not sure about your answer. 
Teacher Perceptions and Attitudes Survey

Part 1: The following list of statements, characterize various aspects of attitudes towards diversity in the classroom. Please choose one that best reflects your belief for each statement.

1. I find teaching a culturally diverse group rewarding.

$\square$ Strongly Disagree

$\square$ Disagree

$\square$ Uncertain

$\square$ Agree

$\square$ Strongly Agree

2. Teaching methods need to be adapted to meet the needs of a culturally diverse student group.

$\square$ Strongly Disagree

$\square$ Disagree

$\square$ Uncertain

$\square$ Agree

$\square$ Strongly Agree

3. Sometimes I think there is too much emphasis placed on multicultural awareness and training for teachers.

$\square$ Strongly Disagree

$\square$ Disagree

$\square$ Uncertain

$\square$ Agree

$\square$ Strongly Agree

4. Teachers have the responsibility to be aware of their students' cultural backgrounds.

$\square$ Strongly Disagree

Disagree

$\square$ Uncertain

$\square$ Agree

$\square$ Strongly Agree

5. It is the teacher's responsibility to invite extended family members (e.g., cousins, grandparents, godparents, etc.) to attend parent-teacher conferences.

$\square$ Strongly Disagree

Disagree

$\square$ Uncertain

$\square$ Agree

$\square$ Strongly Agree 
6. It is not the teacher's responsibility to encourage pride in one's culture.

$\square$ Strongly Disagree

$\square$ Disagree

Uncertain

Agree

Strongly Agree

7. As classrooms become more culturally diverse, the teacher's job becomes increasingly challenging.

$\square$ Strongly Disagree

$\square$ Disagree

Uncertain

Agree

$\square$ Strongly Agree

8. I believe the teacher's role needs to be redefined to address the needs of students from culturally different backgrounds.

$\square$ Strongly Disagree

$\square$ Disagree

Uncertain

$\square$ Agree

$\square$ Strongly Agree

9. When dealing with bilingual students, some teachers may misinterpret different communication styles as behavior problems.

$\square$ Strongly Disagree

$\square$ Disagree

Uncertain

$\square$ Agree

$\square$ Strongly Agree

10. As classrooms become more culturally diverse, the teacher's job becomes increasingly rewarding.

Strongly Disagree

Disagree

Uncertain

Agree

$\square$ Strongly Agree 
11. I can learn a great deal from students with culturally different backgrounds.

$\square$ Strongly Disagree

$\square$ Disagree

Uncertain

$\square$ Agree

$\square$ Strongly Agree

12. Multicultural training for teachers is not necessary.

Strongly Disagree

$\square$ Disagree

Uncertain

Agree

$\square$ Strongly Agree

13. In order to be an effective teacher one needs to be aware of cultural differences present in the classroom.

$\square$ Strongly Disagree

Disagree

$\square$ Uncertain

$\square$ Agree

$\square$ Strongly Agree

14 Multicultural awareness training can help me work more effectively with a diverse student population.

$\square$ Strongly Disagree

Disagree

Uncertain

Agree

$\square$ Strongly Agree

15. Students should learn to communicate in English only.

$\square$ Strongly Disagree

$\square$ Disagree

$\square$ Uncertain

$\square$ Agree

$\square$ Strongly Agree

16. Today's curriculum gives undue importance to multiculturalism and diversity.

$\square$ Strongly Disagree

$\square$ Disagree

$\square$ Uncertain

$\square$ Agree

$\square$ Strongly Agree 
17. I am aware of the diversity of cultural backgrounds of the students I am working with.

$\square$ Strongly Disagree

$\square$ Disagree

$\square$ Uncertain

$\square$ Agree

$\square$ Strongly Agree

18. Regardless of the racial and ethnic make up of my class, it is important for all students to be aware of multicultural diversity.

$\square$ Strongly Disagree

$\square$ Disagree

Uncertain

$\square$ Agree

$\square$ Strongly Agree

19. Being multiculturally aware is not relevant for the students I teach.

$\square$ Strongly Disagree

$\square$ Disagree

$\square$ Uncertain

$\square$ Agree

$\square$ Strongly Agree

20. Teaching students about cultural diversity will only create conflict in the classroom.

$\square$ Strongly Disagree

$\square$ Disagree

$\square$ Uncertain

$\square$ Agree

$\square$ Strongly Agree

Part 2: The following list of statements, characterize various aspects of social attitudes. Please choose one that best reflects your belief for each statement.

21. I generally find it stimulating to spend an evening talking with people from another culture.

$\square$ Strongly Disagree

$\square$ Disagree

$\square$ Uncertain

$\square$ Agree

$\square$ Strongly Agree 
22. I feel an obligation to speak out when I see our government doing something I consider wrong.
$\square$ Strongly Disagree
$\square$ Disagree
$\square$ Uncertain
Agree
$\square$ Strongly Agree

23. The United States is enriched by the fact that it is comprised of many people from different cultures and countries
$\square$ Strongly Disagree
Disagree
$\square$ Uncertain
$\square$ Agree
$\square$ Strongly Agree

24. Really, there is nothing I can do about the problems of the world.
$\square$ Strongly Disagree
Disagree
$\square$ Uncertain
$\square$ Agree
$\square$ Strongly Agree

25. The needs of the United States must continue to be our highest priority in negotiating with other countries

$\square$ Strongly Disagree

$D$ Disagree

$\square$ Uncertain

$\square$ Agree

$\square$ Strongly Agree

26. I often think about the kind of world we are creating for future generations.

$\square$ Strongly Disagree

$D$ Disagree

$\square$ Uncertain

Agree

$\square$ Strongly Agree 
27. When I hear that thousands of people are starving in an African country, I feel very frustrated.

$\square$ Strongly Disagree

Disagree

Uncertain

$\square$ Agree

$\square$ Strongly Agree

28. Americans can learn something of value from all different cultures.

$\square$ Strongly Disagree

Disagree

Uncertain

$\square$ Agree

$\square$ Strongly Agree

29. Generally, an individual's actions are too small to have a significant effect on the ecosystem.

$\square$ Strongly Disagree

$\square$ Disagree

$\square$ Uncertain

Agree

$\square$ Strongly Agree

30. Americans should be permitted to pursue the standard of living they can afford if it only has a slight negative impact on the environment.

$\square$ Strongly Disagree

$\square$ Disagree

$\square$ Uncertain

Agree

$\square$ Strongly Agree

31. I think of myself, not only as a citizen of my country, but also as a citizen of the world.
Strongly Disagree
Disagree
$\square$ Uncertain
Agree
$\square$ Strongly Agree

32. When I see the condition some people in the world live under, I feel a responsibility to do something about it.

$\square$ Strongly Disagree

$\square$ Disagree

$\square$ Uncertain

$\square$ Agree 
$\square$ Strongly Agree

33. I enjoy trying to understand people's behavior in the context of their culture.

Strongly Disagree

Disagree

Uncertain

Agree

Strongly Agree

34. My opinions about national policies are based on how those policies might affect the rest of the world as well as the United States.

$\square$ Strongly Disagree

$D$ Disagree

$\square$ Uncertain

Agree

$\square$ Strongly Agree

35. It is very important to me to choose a career in which I can have a positive effect on the quality of life for future generations.

$\square$ Strongly Disagree

$\square$ Disagree

$\square$ Uncertain

$\square$ Agree

$\square$ Strongly Agree

36. America values are probably the best.

$\square$ Strongly Disagree

Disagree

Uncertain

$\square$ Agree

$\square$ Strongly Agree

37. In the long run, America will probably benefit from the fact that the world is becoming more interconnected

Strongly Disagree

Disagree

Uncertain

Agree

Strongly Agree

38. The fact that a flood can kill 50,000 people in Bangladesh is very depressing to me.

$\square$ Strongly Disagree

$\square$ Disagree

$\square$ Uncertain

Agree

$\square$ Strongly Agree 
39. It is important that American universities and colleges provide programs designed to promote understanding among students of different ethnic and cultural backgrounds.

$\square$ Strongly Disagree

Disagree

$\square$ Uncertain

Agree

$\square$ Strongly Agree

40. I think my behavior can impact people in other countries.

$\square$ Strongly Disagree

Disagree

Uncertain

Agree

$\square$ Strongly Agree

41. The present distribution of the world's wealth and resources should be maintained because it promotes survival of the fittest.

$\square$ Strongly Disagree

Disagree

Uncertain

Agree

$\square$ Strongly Agree

42. I feel a strong kinship with the worldwide human family.

$\square$ Strongly Disagree

Disagree

Uncertain

Agree

$\square$ Strongly Agree

43. I feel very concerned about the lives of people who live in politically repressive regimes.

Strongly Disagree

Disagree

Uncertain

Agree

$\square$ Strongly Agree 
44. It is important that we educate people to understand the impact that current policies might have on future generations.

$\square$ Strongly Disagree

Disagree

Uncertain

$\square$ Agree

Strongly Agree

45. It is not really important to me to consider myself as a member of the global community.

$\square$ Strongly Disagree

Disagree

Uncertain

$\square$ Agree

$\square$ Strongly Agree

46. I sometimes try to imagine how a person who is always hungry must feel.

Strongly Disagree

$D$ Disagree

$\square$ Uncertain

Agree

$\square$ Strongly Agree

47. I have very little in common with people in underdeveloped nations.

$\square$ Strongly Disagree

$\square$ Disagree

Uncertain

$\square$ Agree

$\square$ Strongly Agree

48. I am able to affect what happens on a global level by what I do in my own community.

$\square$ Strongly Disagree

$\square$ Disagree

$\square$ Uncertain

$\square$ Agree

$\square$ Strongly Agree

49. I sometimes feel irritated with people from other countries because they don't understand how we do things here.

$\square$ Strongly Disagree

Disagree

Uncertain

Agree

Strongly Agree 
50. Americans have a moral obligation to share their wealth with the less fortunate people of the world.

$\square$ Strongly Disagree

$\square$ Disagree

$\square$ Uncertain

$\square$ Agree

$\square$ Strongly Agree

Part 3: Demographic information

51. Gender:

$\square \mathrm{F}$

$\square \mathrm{M}$

52. Age:

53. Ethnicity:

$\square$ African American

$\square$ Caucasian

$\square$ Hispanic

$\square$ Asian

$\square$ Native American

$\square$ Other

54. Program:

$\square$ In-service

$\square$ Post Bac

$\square$ 5-Year

55. Teaching Experience:

Levels Taught: (Check all that apply.)

$\square$ PreK

$\square$ Elementary

$\square$ Secondary

Total Years Taught

56. Have you had any international travel/study abroad?

$\square$ No

$\square$ Yes Please describe 
57. What is your religious persuasion/ worldview?
Christian
$\square$ Jewish
$\square$ Muslim
$\square$ Spiritual

$\square$ Other

58. How many courses have you taken that dealt with global and multicultural issues?

59. What languages do you speak?

60. What has been your exposure to diversity in the US? Use reverse side if need be. 


\section{APPENDIX C}

Permission Letters to Dean and Faculty of Human Resources \& Education 
Dr. Anne Nardi, Dean

West Virginia University

College of Human Resources and Education

Dear Dr. Nardi,

I am seeking permission from the College of Human Resources and Education to conduct dissertation research. I intend to administer a one-time attitudinal survey instruments to a section of the $5^{\text {th }}$ year, and Post Baccalaureate teacher candidates during the fall semester.

In accordance with established University policy, I will obtain consent from the Human Subjects Committee of the Institutional Review Board to conduct research.

Upon completion of my research and the final dissertation product, the dissertation will be submitted electronically and available for your perusal.

I am requesting your approval for permission to conduct dissertation research as outlined above.

Approved Date

Dean Anne Nardi 


\section{Dear Dr.}

I am seeking permission to conduct dissertation research. I intend to administer a onetime attitudinal survey instruments to your students during the fall semester.

In accordance with established University policy, I will obtain consent from both the Dean of the College of Human Resources and Education and the Human Subjects Committee of the Institutional Review Board to conduct research.

Upon completion of my research and the final dissertation product, the dissertation will be submitted electronically and available for your perusal.

I am requesting your approval for permission to conduct dissertation research as outlined above.

Approved Date

Denied Date 
Ras Tsidi Acolatse, Ed.D

21870 Maywood Terrace Sterling, VA 20164 rastaco@hotmail.com 703-376-7178

\section{Education:}

May 2010

West Virginia University, Morgantown, WV

Candidate for Doctorate of Education in Curriculum \& Instruction

Minor in Communication Studies

Dissertation: Global mindedness and dispositions towards cultural diversity in the classroom.

Sep $2001 \quad$ Emerson College, Boston, MA

Master of Arts in Management \& Organizational Communication

Minor in Global Corporate Training and Development

Project: Achieving Intercultural Management Competence: The Role of

Management Training and Best Practices.

Dec $1997 \quad$ University of Ghana, Legon, Ghana

Graduate Diploma in Mass Communication Studies

Focus on Advertising and Public Relations

Thesis: The Influence of Celebrity Endorsement in TV Commercials on Teenage Viewers: A Case Study of the Parlays Biscuit Commercial.

Dec 1993 University of Cape Coast, Cape Coast, Ghana

Bachelor of Arts \& Diploma in Education

Senior Thesis: The Foregrounding of Imagery in Selected East African Poetry as Expressions of Social Disparity and the Indifference of the Rich to the Poor.

\section{Relevant Functional Experience:}

\section{Instructional Leadership}

- Over 10 years of successful and reflective experience as a general education and communication practitioner at various universities and colleges.

- Exceptional record of accomplishment as a lead faculty and associate area chair for a major player in the for-profit higher education marketplace.

Faculty \& Personnel Development

- Progressively and successfully responsible for recruiting, training, mentoring, and evaluating faculty performance.

- Developed and deployed training modules for faculty with the view to maintaining faculty effectiveness, efficiency, and integrity.

- Contracted and scheduled faculty to teach assigned courses

- Motivated faculty to teach according to stipulated standards while giving them enough latitude to be creative and innovative. 
- Responsible for recruiting, training and mentoring Summer interns who were very instrumental in looking for country specialists, organizing training materials, and setting up training and video conferencing rooms

\section{Curriculum Design \& Implementation}

- Instrumental in designing balanced theoretical and career-focused curriculum for traditional and non-traditional students.

- Constantly evaluated course delivery modules and recommended significant changes based on contemporary scholarship and industry demands.

- A key player on a team responsible for designing and reviewing cross-cultural and global organizational development training programs.

\section{Program Management \& Consulting}

- Ably assisted the Director of Training in managing contractual cross-cultural training programs for fortune 500 companies, which comprised interfacing with clients, assessing training needs, recommending appropriate curriculum, looking for country specialists, scheduling training times, and evaluating feedback from participants.

- Instrumental in designing and deploying cross-cultural audits and other psychometric instruments for fortune 500 companies with the view to ascertaining and fine-tuning their cross-cultural and global organization preparedness.

- A key player in coordinating and integrating the communication and cross-cultural needs of a US-based non-profit organization.

- Successfully directed and managed the affairs of a non-profit organization responsible for inculcating and equipping high school students with intercultural knowledge, skills, and competencies germane to living and working in an increasingly globalized world.

\section{Program \& Product Positioning}

- A rich history of revamping and repositioning the brand personality of goods and services at an international ad agency by orchestrating a mix of perceptive and punchy media strategies.

- Instrumental in reviving existing but dormant clubs of an intercultural exchange program by shoring up their visibility in the community through a series of well-calculated events and advertorials.

\section{Relevant Job History:}

General Education Instructional \& Leadership History

2008 to Current Faculty, Westwood College, VA

2006 to Current Lead Faculty \& Associate Area Chair, University of Phoenix

2003 to 2007 Teaching Fellow at West Virginia University, Glenville State College, \& West Virginia Wesleyan College 


\section{Industry \& Related Program Management Experience}

Cross-Cultural Communication Consultant/Trainer/Grants \& Proposal Writer, Nation Children Inc.

Herndon, VA 2007- to current

Program Manager/Cross-Cultural Trainer/Global Organizational Development Consultant, Eaton Consulting Group (now Aperian Global), Boston, Massachusetts, May 2001-August 2004.

Senior Client Service Executive, Ghana Advertising \& Marketing Limited, an Affiliate of J. Walter Thompson Worldwide, Accra, Ghana/New York, NY. 1996-1999.

Regional Director, The Intercultural Exchange Program/American Friendship Society, Cape Coast, Ghana, 1994-1996

\section{Other Relevant Experience and Information}

\section{International Program Development and Partnership:}

\section{West Virginia University International Programs}

Served on committee tasked with shoring up the visibility and attractiveness of WVU to students in Africa as well as establishing partnerships with universities on the continent.

\section{National Accreditation Experience:}

Instrumental in collecting, collating and co-authoring a successful report for NCATE accreditation for the College of Human Resources \& Education at the West University, Morgantown, WV.

\section{Academic Mentoring For Students}

McNair Scholars Program, West Virginia University, Summers 2003 \& 2004.

Graduate Mentor

-Monitored the scholars' research activities and provided feedback and guidance.

Health Career Opportunities Program, West Virginia University, Summer 2004.

Graduate Mentor

-Met regularly with students to discuss study and time management skills

-Monitored students' work and gave them constructive feedback

Health Science \& Technology Academy, West Virginia University, Summer 2003.

Graduate Mentor

-Met regularly with mentees to motivate and encourage them to stay the course.

- Supervised and chaperoned mentees in both structured and unstructured environments. 
Awards

2004 - 2008 National Dean’s List

2004

Service-Above-Self Scholarship, Institute for Communication Improvement

1999-2001 Graduate Merit Assistantship, Emerson College, Boston, MA

2001

Outstanding Resident Assistant, Emerson College, Boston MA

1996

Best Teacher, Wesley Girls’ High School, Cape Coast, Ghana

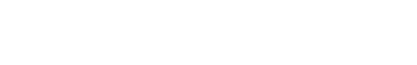

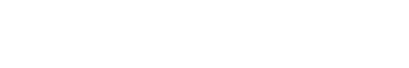

